Estudios sobre armas antiguas, arte militar $\mathrm{y}$ vida cultural en oriente y occidente

XL (2020), pp. 153-181

ISSN: 0436-029X; eISSN: 1988-4168

https://doi.org/10.3989/gladius.2020.07

\title{
FRANCESES CONTRA BRITÁNICOS EN EL PUENTE DE MARIALBA. HISTORIA Y ARQUEOLOGÍA DE UN EPISODIO DE LA GUERRA DE LA INDEPENDENCIA EN GALLEGOS DE ARGAÑÁN, SALAMANCA*
}

\author{
FRENCH AGAINST BRITISH ON THE MARIALBA BRIDGE. \\ HISTORY AND ARCHEOLOGY OF AN EPISODE OF THE PENINSULAR WAR \\ IN GALLEGOS DE ARGAÑÁN, SALAMANCA
}

POR

Clemente González García**

\section{RESUMEN - ABSTRACT}

En 2018 se ejecutó la II Fase del proyecto de investigación Campos de Batalla en Gallegos de Argañán, Salamanca, ss. XVII - XIX, basada en la prospección intensiva de grandes áreas mediante detector de metales. Se han documentado varios miles de objetos metálicos y en concreto, una gran concentración de proyectiles esféricos en torno al puente de Marialba. La investigación histórica ha permitido vincular esos hallazgos con un episodio ocurrido entre tropas británicas y francesas, el 23 de abril de 1811, poco antes de la batalla de Fuentes de Oñoro. Las concentraciones de disparos de diferentes calibres permiten identificar los emplazamientos de las tropas sobre ambas orillas. Al mismo tiempo, los diferentes grados de deformación que presentan los proyectiles podrían ser indicadores de la distancia a la que se realizaron los disparos y por consiguiente, de la intensidad de la lucha en cada lugar.

In 2018, the II Phase of the research project Battle Fields in Gallegos de Argañan, Salamanca, ss XVII - XIX, based on intensive prospecting of large areas through a metal detector was executed. Several thousand metal objects have been documented and in particular, a large concentration of spherical lead balls around the Marialba bridge. Historical research has allowed linking these findings with an episode between British and French troops, on April 23, 1811, shortly before the battle of Fuentes de Oñoro. The concentrations of shots of different calibers allow to identify the locations of the troops on both banks. At the same time, the different degrees of deformation that the projectiles present could be indicators of the distance at which the shots were made and, consequently, of the intensity of the fight in each place.

\section{Palabras Clave - Keywords} Rodrigo.

Arqueología de los campos de batalla; detector de metales; Guerra de la Independencia; Salamanca; Ciudad

Battlefield archaeology; metal detector; Peninsular War; Salamanca; Ciudad Rodrigo.

\section{Cómo citar este ARtículo / Citation}

González García, C. (2020): «Franceses contra británicos en el puente de Marialba. Historia y arqueología de un episodio de la Guerra de la Independencia en Gallegos de Argañán, Salamanca». Gladius, 40: 153-181. https:// doi.org/10.3989/gladius.2020.07

* Proyecto de Investigación Campos de Batalla en Gallegos de Argañán, Salamanca, ss XVII - XIX, hasta la fecha, autofinanciado.

** Investigador independiente. cgg5550@gmail.com / ORCID iD: http://orcid.org/0000-0001-9931-5480 


\section{INTRODUCCIÓN}

Es de sobra conocido que la actividad bélica durante la Guerra de la Independencia en la provincia de Salamanca alcanzó niveles de enorme intensidad. Los dos asedios de Ciudad Rodrigo o las batallas de Tamames, Fuentes de Oñoro, Arapiles, etc., constituyen algunos de los más destacados episodios de esa larga y cruel contienda. De ahí que las páginas dedicadas a conocer el desarrollo de estos memorables hechos de armas sean también muy numerosas. Sin embargo, además de estos grandes episodios se produjeron muchísimos otros de menor entidad. Breves combates de pocas horas o escaramuzas más o menos intensas cuyo rastro también se puede seguir en la documentación de época. No causaron cifras tan elevadas de bajas pero sí un continuo goteo de muertos y heridos.

Gracias a la arqueología de los campos de batalla estamos comenzando a documentar de forma rigurosa los restos que existen en los escenarios bélicos y a través de ellos contrastar la veracidad de los testimonios documentales. Este artículo gira en torno a un breve episodio ocurrido en un escenario estratégico: el puente de Marialba sobre la rivera de Azaba a pocos $\mathrm{km}$ de Ciudad Rodrigo. En los alrededores de dicho puente se enfrentaron en varias ocasiones, entre 1810 y 1811, la División Ligera del general Robert Craufurd contra diversas unidades francesas del Ejército de Portugal.

\section{LA FASE II. DESARROLLO Y RESULTADOS}

En el verano de 2017 comenzamos el trabajo de campo de nuestro proyecto de investigación denominado Campos de batalla en Gallegos de Argañán, ss. XVII-XIX, del cual ya explicamos el fundamento y la metodología empleada al publicar los hallazgos de la Fase I (González, 2018).

Durante los meses de mayo y agosto de 2018 procedimos a ejecutar la prospección intensiva con detector de metales correspondiente a la Fase $\mathrm{II}^{1}$. La zona delimitada para el trabajo de campo forma un rectángulo de unos de $4,5 \mathrm{~km}$ de longitud por 1 de anchura. Se sitúa a caballo del antiguo camino de Ciudad Rodrigo, en el tramo comprendido entre el casco urbano de Gallegos de Argañán y el límite oriental del municipio. Una zona en la cual la rivera de Azaba vierte sus aguas en el río Águeda.

El trabajo de campo se desarrolló en dos etapas. Se inició en primavera y se concluyó en pleno verano. Las intensas lluvias caídas en la zona a finales de abril provocaron que la tierra estuviera muy blanda y húmeda, lo cual favoreció mucho el trabajo con el detector de metales. Sin embargo, también dieron lugar a que, en apenas 15 días, la vegetación se desarrollara de manera extraordinaria, hasta el punto de que llegó a ser imposible recorrer muchas parcelas con el detector. Además de esto, fue imposible acceder a una buena parte del terreno debido a que se encontraba sembrado de cereal y en el mes de mayo aparecía ya muy brotado. Por tanto, hubo que esperar a que los campos estuvieran cosechados y que el ganado diera buena cuenta de los rastrojos, para continuar la prospección durante el mes de agosto. En total, entre ambos meses se dedicaron al trabajo de campo 298 horas.

En la mayoría de las parcelas el terreno resultó ser muy llano, lo que favoreció una prospección muy regular, con transectos separados $3 \mathrm{~m}$ uno de otro. Sin embargo, no se pudo aplicar la misma regularidad en las zonas próximas a la rivera, debido a los fuertes desniveles $\mathrm{y}$, sobre todo, a la presencia de numerosas encinas, abundante vegetación arbustiva y suelo

\footnotetext{
1 Autorización de la Junta de Castilla y León 2/2018-SA.
} 


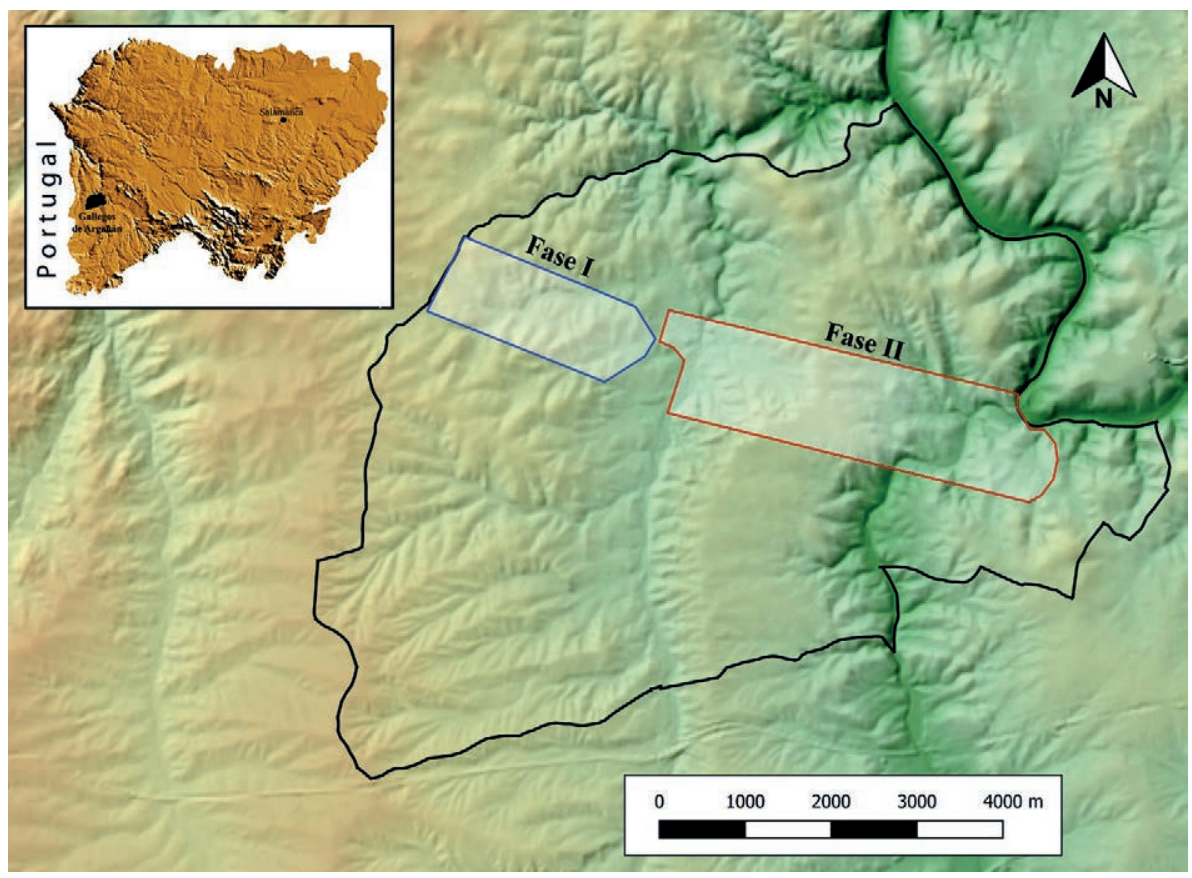

Figura 1. Mapa de situación. Provincia de Salamanca y relieve del término municipal de Gallegos de Argañán con la ubicación de las zonas prospectadas en cada fase. Clemente González 2020.

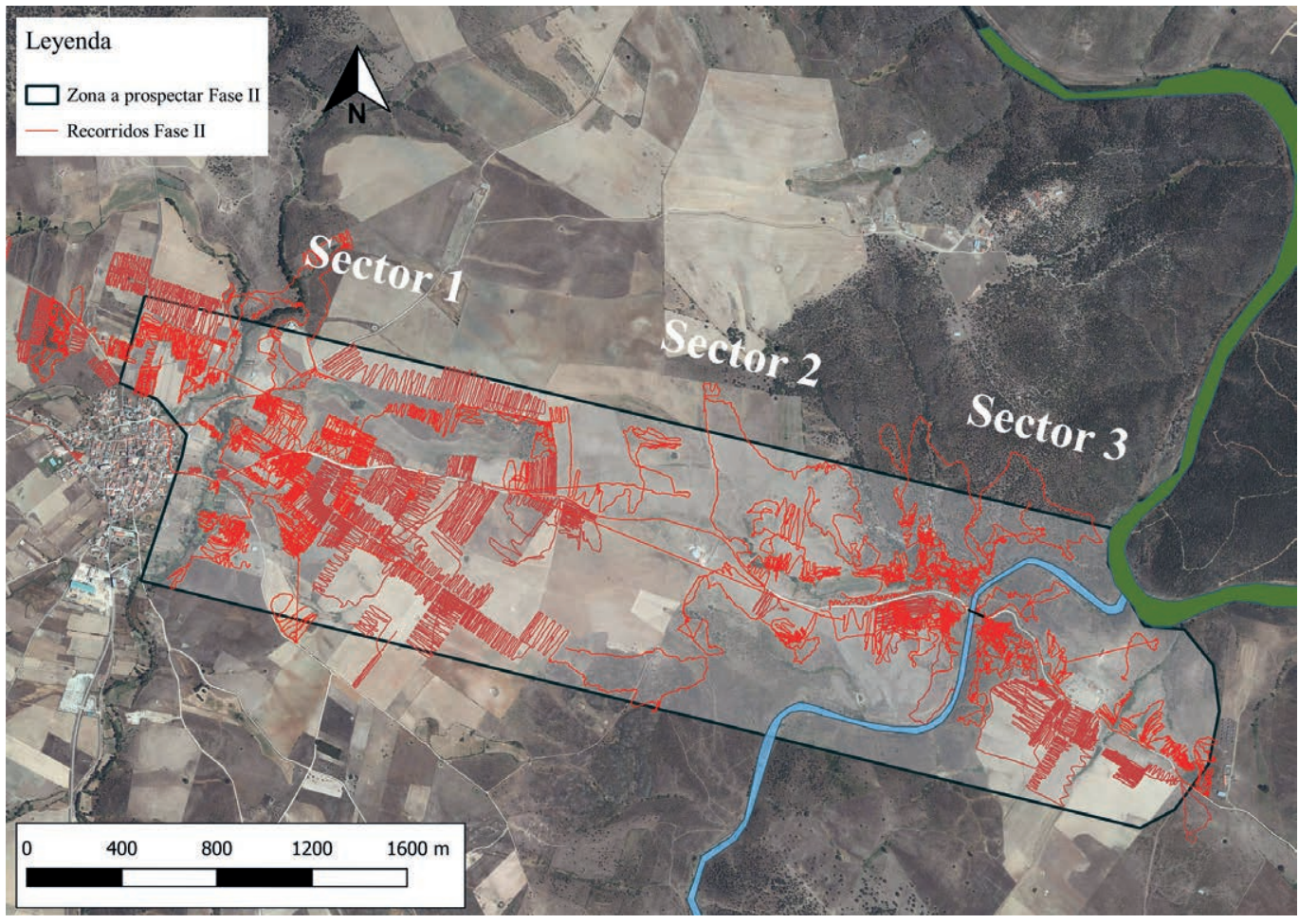

Figura 2. Ortofotografía aérea (CNIG) de la zona prospectada en la Fase II y cobertura de la misma. Clemente González 2020. 
rocoso. En esta zona se prospectaron solo aquellos espacios que resultaron accesibles sin implicar riesgos para la seguridad del operador.

Los resultados de la Fase II han sido extraordinarios. Se han documentado casi 2.000 objetos metálicos. Entre ellos destacan, tal como se sintetiza en la figura 3, 780 proyectiles esféricos, 382 monedas, 117 botones y numerosas piezas de origen romano, en su mayoría localizadas en el entorno del asentamiento de Marialba.

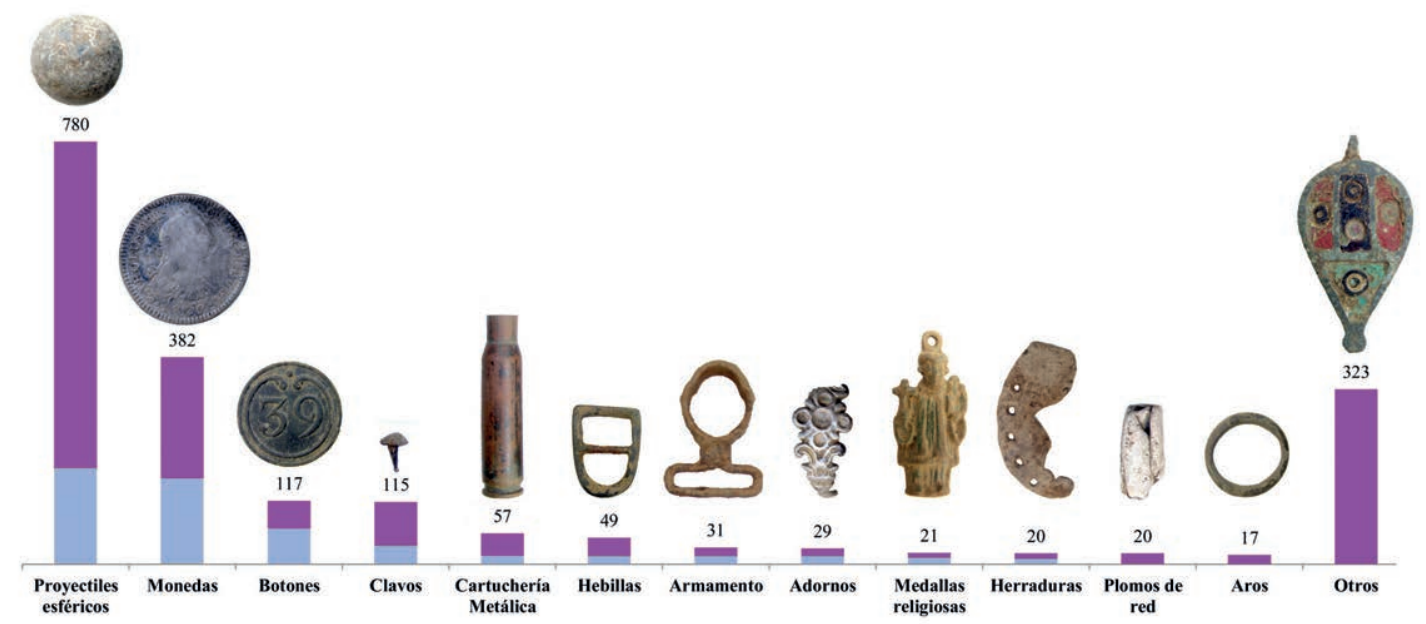

Figura 3. Síntesis del material documentado en la Fase II. En tono claro las cantidades recuperadas en la Fase I. Clemente González 2020.

El terreno a recorrer se estructuró en tres sectores, siendo el mejor prospectado y el más fructífero el primero. Sin embargo, dedicaremos este artículo a los materiales documentados en el tercer sector, el comprendido entre las fincas de Marialba y La Puentecilla ${ }^{2}$. En dicha zona se ha documentado un escenario de combate, con abundante intercambio de disparos de armas de diferentes calibres. La investigación histórica realizada al respecto permite vincular estos hallazgos con un episodio muy concreto ocurrido en abril de 1811.

\section{MARIALBA Y EL PUENTE DE LA AZABA: ANTECEDENTES HISTÓRICOS DE ACTI- VIDAD BÉLICA}

La finca de Marialba está integrada en el término municipal de Gallegos de Argañán, pero no siempre fue así. En 1752, fecha en la que se elaboró el Catastro de Ensenada, aún estaba vinculada a Carpio. Era lugar de realengo y dividía su territorio en tres hojas o tierras de labor llamadas de la Rivera, de la Atalaya y de Val de Sancho. Esta última sobre la orilla izquierda del Águeda y lindante con Palacios. En la fecha citada no había más árboles en la finca que unos pocos álamos negrillos, los cuales crecían junto a las dos únicas casas existentes. En ellas vivían cinco vecinos, siendo 26 el número total de personas que habitaban o trabajaban en Marialba. El mismo documento reconoce la existencia del puente al indicar los límites de la finca: «poniente por la rivera de Azaba y puente que sobre ella se halla» (González, 2015: 152-153).

\footnotetext{
2 El autor agradece públicamente a los propietarios de las fincas de Marialba y La Puentecilla las facilidades prestadas para desarrollar esta investigación.
} 
Precisamente merece la pena dedicar también algunas líneas a esta estructura, imprescindible para salvar el cauce de la rivera de Azaba. La obra, tal como se conserva en la actualidad, consta de cuatro arcos semicirculares de piedra labrada en sillares, de diferentes dimensiones. $\mathrm{Su}$ longitud ronda los $50 \mathrm{~m}$ y el arco mayor tiene una luz en torno a los $8 \mathrm{~m}$. El más pequeño de los arcos se encuentra situado fuera del cauce, sobre la orilla derecha. Del mismo material y técnica que los arcos son los tajamares y contra tajamares. Estos últimos presentan planta semicircular mientras que el tajamar central es de planta triangular. En cambio, los muros que se alzan sobre los arcos están formados, en su mayoría, de mampuesto de pizarra. También lo son los pretiles en los que se aprecian señales de diversas reparaciones ${ }^{3}$.

A tenor de los abundantes restos romanos documentados durante nuestra prospección en la propia finca de Marialba, es muy probable que en el lugar existiera un puente romano. Sin embargo, conviene tener presente que la intensa despoblación que sufrió la zona tras la caída del Imperio, así como la falta de mantenimiento de estas grandes obras públicas, provocó su progresivo deterioro. En este sentido, merece la pena tener presente uno de los casos mejor documentados en la zona. El denominado puente romano de Ciudad Rodrigo, que ya en la Edad Media estaba derruido. Reconstruido por Fernando II al repoblar la ciudad se arruinó varias veces más por las grandes riadas del Águeda. En 1549 volvió a derribarse. Y la reparación, realizada con maderas, apenas aguantó diez años hasta que otra riada, en diciembre de 1558, arrancó todo y se lo llevó. El concejo acordó llamar a los mejores maestros y arquitectos, entre ellos Pedro de Ibarra, quien tasó la obra del puente en 31.640 ducados. Por su excesivo coste se requería la autorización de la Corona para repartir el gasto entre todas las poblaciones del Alfoz. La obra se hizo en 1560 con piedra traída de Villar del Rey (Hernández, 1935: I, 234; II, 12 y 53). Se indican todos estos datos porque la tipología del puente de la Azaba, aunque de dimensiones más reducidas, resulta similar a la del puente viejo de Ciudad Rodrigo. Parece muy probable que ambos fueran construidos en esta época de bonanza económica del siglo XVI, aunque en sus cimientos ya existieran obras más antiguas. Además, hay que tener en cuenta que las guerras sufridas en la comarca contra Portugal fueron numerosas y continuas. Solo la del siglo XVII duró 28 años, dejando totalmente arrasada la tierra, las casas, ermitas, etc. del Campo de Argañán. Al siglo siguiente, volvió a repetirse el fenómeno con la Guerra de Sucesión que se prolongó una década, que arrasó el puente de Ciudad Rodrigo y que mantuvo completamente abandonada la finca de Marialba entre 1705 y 1710 (González, 2015: 131).

En cualquier caso, sea cual sea su origen, es indudable que dicho puente constituye un punto de interés estratégico, tanto militar como comercial. El puente permite la continuidad del camino que, desde Ciudad Rodrigo, llega hasta Gallegos de Argañán y sigue luego hacia la frontera portuguesa. Es comprensible, por tanto, que los materiales documentados en su entorno presenten una amplia cronología. Se ha localizado desde un glande romano hasta proyectiles disparados por la Guardia Civil a finales de los años 80 del pasado siglo $\mathrm{XX}^{4}$. Sin embargo,

3 En junio de 1808 y tras conocerse los sucesos ocurridos el 2 de mayo en Madrid, la Junta de Armamento y Defensa de Ciudad Rodrigo tomó numerosas medidas para impedir que las tropas francesas que estaban en Portugal atacaran la plaza. Una de ellas designar al comandante de artillería Chacón y al capitán de ingenieros Nicolás Verdejo, «pasasen a cortar el puente de Marialba y cortar los vados» (https://rodericense.blogspot.com/2015/08/una-carta-sobre-los-acontecimientos-de.html. Consulta 31-VIII-2019).

4 Sobre ambas orillas de la rivera de Azaba se recuperaron 33 proyectiles de $9 \mathrm{~mm}$ y nueve de 7,62 $\mathrm{mm}$. Estos últimos fueron, sin duda, disparados por fusiles de asalto Cetme pues, además, se recuperaron dos vainas de 7,62 x 51 fabricadas por Santa Bárbara en 1982 y 1983. En cuanto a la munición de arma corta también se recuperaron tres vainas de $9 \mathrm{~mm}$ Parabellum. Una de ellas fabricada por Santa Bárbara en 1984, otra por la alemana Dynamit Aktien Gesellchaft, y otra producida en Filipinas en 1986 por la Arms Corporations of Philipines. Esta última pertenecería al lote de cuatro millones de cartuchos adquirido para la Guardia Civil en 1987, que debido a su elevada potencia para usarlos en las pistolas reglamentarias acabaron utilizándose en los subfusiles. (www.munición.org. Consulta 14-III-2109). Los testimonios 


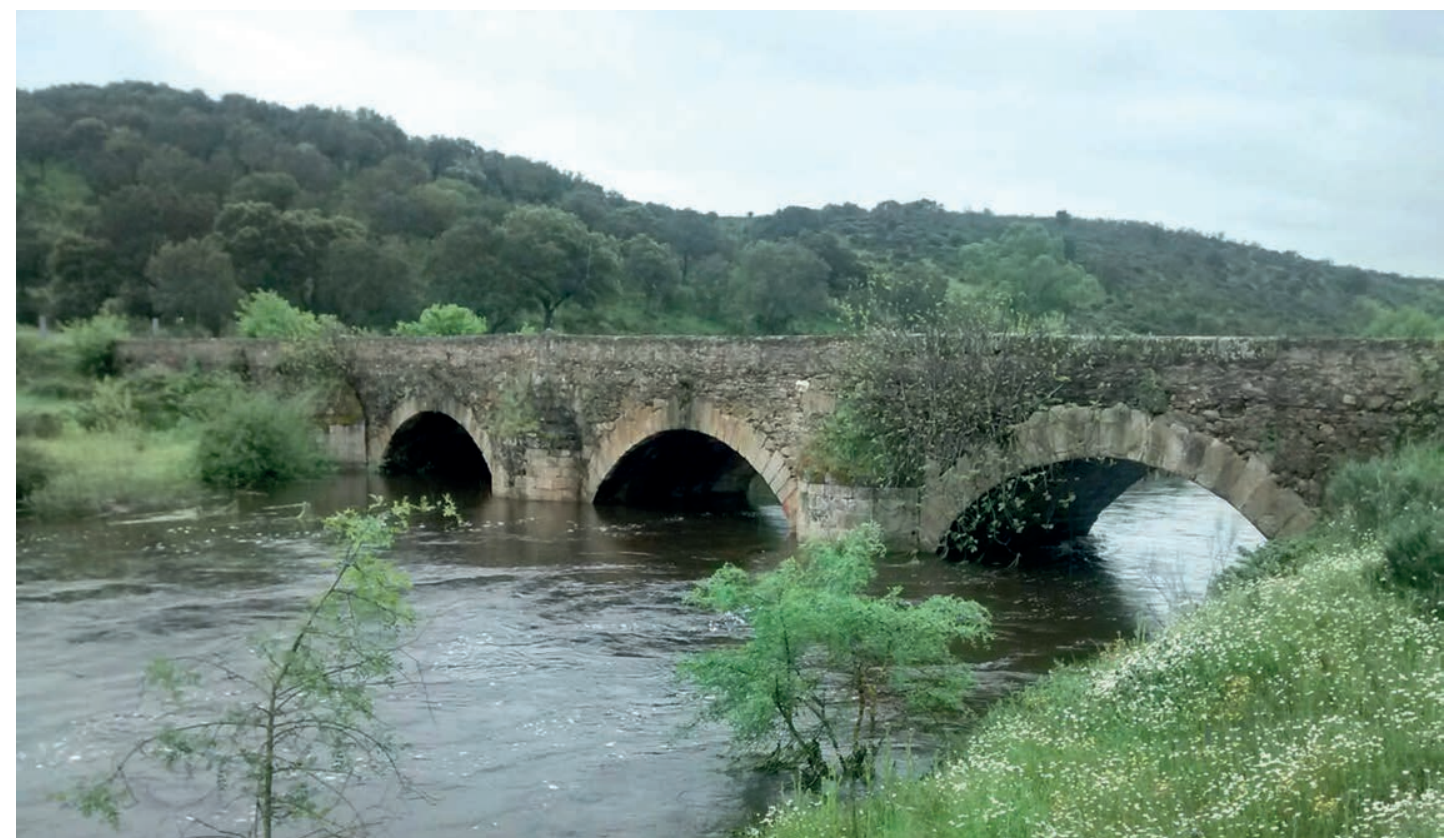

Figura 4. Puente sobre la rivera de Azaba visto desde la orilla izquierda el 23 de abril de 2016. Se aprecia la diferencia entre la obra de arcos y contra tajamares frente a los muros realizados con mampuesto. A la izquierda la cota 626 , posición defensiva francesa hoy poblada de encinas. Clemente González 2016.

nuestra atención se centrará en lo ocurrido en este lugar en los momentos más intensos de la Guerra de la Independencia, básicamente en dos momentos concretos y bien definidos. El primero y de mayor duración, abarca el periodo comprendido entre el asedio de Ciudad Rodrigo y la rendición de Almeida. El segundo se sitúa en la primavera de 1811, concretamente tras la derrota francesa de Sabugal y poco antes de la batalla de Fuentes de Oñoro.

\subsection{PRIMER CICLO DE ACTIVIDAD: PRIMAVERA - VERANO DE 1810}

El 25 de abril de 1810, las primeras tropas francesas del general Mermet se presentaron ante Ciudad Rodrigo y comenzaron las operaciones de bloqueo (Becerra y Redondo, 1988: 45). Pero la primera noticia sobre actividad bélica en el entorno de Marialba ocurre en la mañana del 21 de mayo, cuando una partida inglesa de 600 hombres y 800 caballos, con dos cañones, asaltaron los puestos avanzados de los franceses en el camino de Carpio (Koch, 1850: 71-72).

El 30 de mayo llegaba ante las murallas de Miróbriga el general Mássena y desde ese momento comenzó a ejecutarse el asedio. Precisamente a partir de esa fecha es también cuando los británicos se desplegaron sobre el puente de la Azaba5:

recogidos entre algunos vecinos confirman que los guardias del puesto de Gallegos de Argañán realizaron prácticas de tiro en dicho cauce a finales de los 80 y principios de los 90. Más información en http://www.arqueologiaycamposdebatalla. simplesite.com/444175214.

5 Las citas de textos ingleses o franceses han sido traducidas por el autor. 
Dos compañías de fusileros se colocaron ahora como piquetes arriba, a unas dos millas al frente, sobre el río Azaba, en el puente de Marialba y los fuertes. Al otro lado del río, en una altura dominante en el pueblo de Carpio, se colocó un centinela de los húsares alemanes. Desde su puesto podía controlarlo todo entre él y Ciudad Rodrigo (Simmons, 1899: 71).

El cruce del camino sobre la rivera de Azaba presentaba diversos problemas tácticos que afectaban a ambos ejércitos. El primero era que el lecho de la rivera se encuentra muy encajonado y para poder controlar su paso es necesario situar la vigilancia prácticamente sobre las orillas. Otro, que cualquiera que intentara cruzarlo a la carrera, se beneficiaria de llegar a él cuesta abajo, pero en cambio al pasar a la orilla opuesta se encontraría una larga y continuada cuesta ascendente, agotadora para tropas y animales. Sin olvidar que resultaba muy fácil dominar el tránsito sobre el puente mediante fuegos de flanco, lo peor de todo era que la posición podía ser fácilmente envuelta. Esto último era algo que los británicos sabían perfectamente: «el puente de Marialba podía ser envuelto por un vado por debajo de la confluencia de las dos corrientes» (Napier, 1839: 170-171). Dicho vado, donde los ingleses instalaron su puente de pontones en 1812, era el del Molino de Flores. Sin embargo, mucho más cerca, los franceses emplazaron un puente de tablas que enlazaba directamente con el camino de Sexmiro, tal como se aprecia claramente en el mapa francés de la figura 5.

A comienzos de junio la División Ligera del general Craufurd tenía su cuartel general en Gallegos. Sus patrullas avanzadas se movían entre el río y la rivera vigilando los puestos de

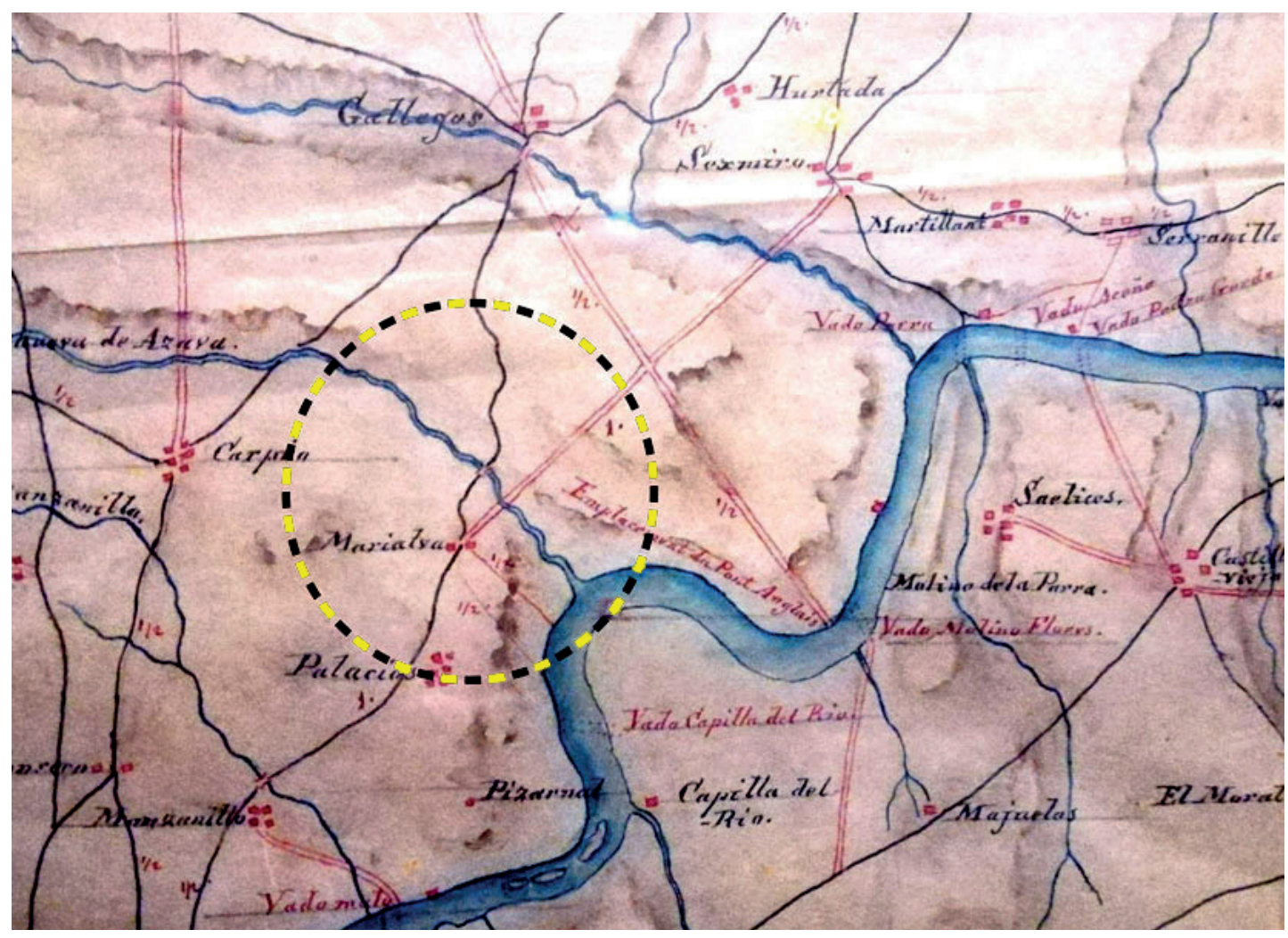

Figura 5. Fragmento del mapa francés del capitán de EM Harmois, realizado en 1800 y actualizado en 1812. No está orientado hacia el norte sino hacia Portugal. Presenta, en trazo doble, las vías alternativas a los caminos tradicionales. Nótese la que sale de Marialba y cruza la rivera de Azaba a la derecha del puente de piedra para enlazar con Sexmiro. Clemente González 2019. 
los franceses situados en la orilla derecha del Águeda. La línea de vigilancia establecida por los británicos consistía en una cadena de puestos a lo largo del cauce de la rivera y luego el del río. De sur a norte, el primero se denominaba Ford Carpio y estaba integrado por un oficial, un sargento, dos cabos y dieciocho hombres de caballería apoyados, durante la noche, por un refuerzo de infantería. Le seguía el Ford Mill, con un oficial, sargento, cabo y dieciocho hombres montados. Luego estaba la posición del puente de Marialba cuyo contingente era idéntico al anterior pero además reforzado con infantería. Finalmente, a 1,5 km al norte del puente estaba el puesto denominado Molino de Flores, el más septentrional y situado ya sobre el cauce del Águeda. Aquí los británicos desplegaban doce hombres de caballería y veinte infantes y cada contingente al mando de un oficial. Además, situados en la retaguardia próxima, contaban con el apoyo de dos cañones de 6 libras y abundantes tropas de refresco (Tomkinson, 1894: 26).

Conviene tener presente que las denominaciones y citas geográficas que transmiten las fuentes británicas, tales como Marialba, Ford Carpio, Molino de Flores, etc., deben entenderse de forma amplia pues para ellos era la manera de aludir a una referencia vecina al punto de despliegue, sin que eso signifique que los centinelas se emplazaran exactamente allí. De lo que no hay duda es que tanto los centinelas franceses como los británicos estaban muy próximos lo que les obligaba a dormir totalmente equipados (Leach, 1831: 134).

A medida que avanzaba el asedio de Ciudad Rodrigo, los franceses también aumentaron su presión sobre los puestos avanzados británicos. Los húsares de la King's German Legion encargados de la vigilancia se vieron envueltos en constantes escaramuzas (Beamish, 1832: 272). El 5 de junio tuvo lugar una de ellas. Esa mañana parte de la caballería francesa cruzó el Águeda por el puente de La Caridad y llegó hasta los puestos británicos de Manzanillo y Marialba, donde se enfrentaron con los húsares que estaban de centinelas (Fitzclarence, 1851: 194).

Desde el 9 de junio había en Marialba un piquete británico integrado por una compañía de infantería y dos días más tarde dicho piquete se incrementó con veinticuatro hombres del Regimiento 95 de Rifles. El 12 de junio el general Craufurd acudió personalmente a inspeccionar los puestos avanzados en Marialba, Carpio y Manzanillo y ordenó a los soldados levantar diversas construcciones defensivas en dichos lugares. Esa misma tarde los franceses se apoderaron de Palacios, finca vecina situada al este de Marialba, así como de la altura de su izquierda, entre las fincas de Capilla y Pizarral (Fitzclarence, 1851: 198).

La posición de Marialba era de gran valor estratégico por la sencilla razón de que en ella se sitúa una de las más destacadas alturas de la zona. La elevación existente al sur de la finca de Marialba, denominada La Atalaya, es en la actualidad vértice geodésico y tiene una cota de $709 \mathrm{~m}$. Desde ella se domina la mayor parte del territorio próximo, incluyendo también la propia población de Ciudad Rodrigo, que dista en línea recta exactamente $10 \mathrm{~km}$. Desde dicha posición los británicos seguían con sus catalejos el desarrollo de las obras de asedio que realizaban los franceses:

Viajé con el coronel Elder a Marialba, y desde lo alto vi a los franceses muy ocupados en el trabajo cerca de su puente en Carboneros. La primera paralela del enemigo, que ayer no se pudo ver debido a la neblina, se observó hoy claramente desde la altura sobre Marialba (Fitzclarence, 1851: 199).

Idéntica importancia visual tenía el punto denominado Molino de Flores, que más que situarlo hundido en el vado del río donde se conservan las ruinas de dicho molino, debe ubicarse en los altos de la finca de Cuellar. Las referencias a este punto como lugar de observatorio para conocer lo que ocurría en Ciudad Rodrigo son abundantísimas, fechándose la primera el 18 de junio: «Dos columnas del enemigo y cerca de 8 piezas de campaña y 80 carros, fueron vistos esta mañana desde Molinos de Flores» (Fitzclarence, 1851: 203). Once días más tarde, el mis- 
mo oficial anotaba en su diario que desde dicho emplazamiento se podía contemplar la brecha abierta por los franceses en la muralla de Ciudad Rodrigo (Fitzclarence, 1851: 210). Algo que sería absolutamente imposible de encontrarse situado en el lecho del río.

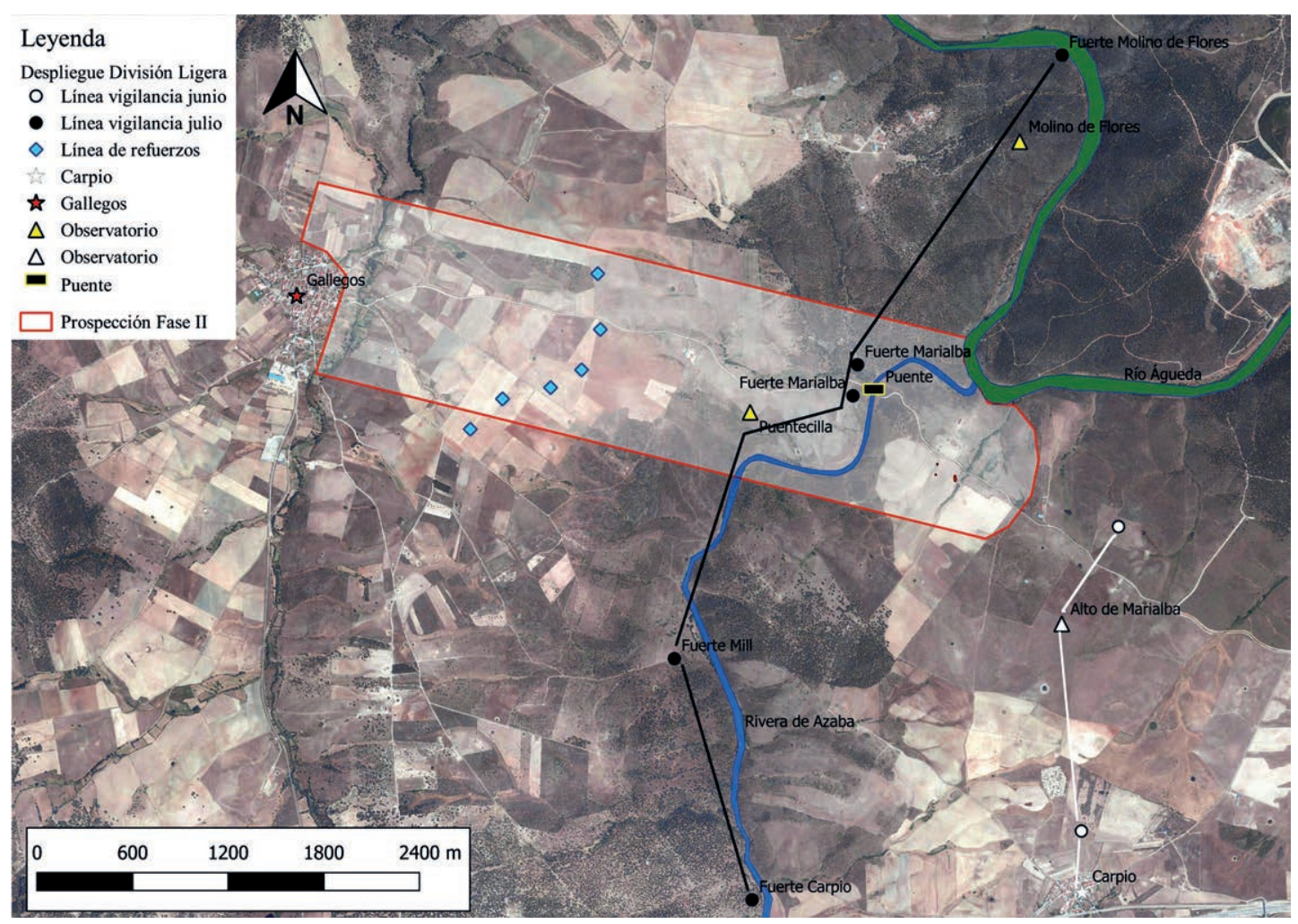

Figura 6. Ortofotografía aérea (CNIG) indicando la zona a prospectar en la Fase II y los puntos de despliegue de la División Ligera británica. Clemente González 2020.

A partir de mediados de junio la presión de los franceses sobre la línea británica en Marialba se volvió continua y prácticamente realizaron un reconocimiento cada dos días. Así, el 19 lanzaron una incursión sobre Carpio y las avanzadas británicas (Simmons, 1899: 72). Dos días más tarde se produjo otra ocasión de enfrentamiento en la misma zona sobre la cual los diarios de combatientes británicos aportan detalles interesantes.

Esta mañana tocaron alarma alrededor de las diez en punto, y la Brigada de Infantería y los húsares se formaron sobre la colina frente a Gallegos, en el camino de Ciudad Rodrigo. Resultó ser solo una partida de forrajeadores a la que disparamos siete bolas de uno de los (cañones) de seis libras. Como si se hubiera alarmado por esto, dos horas después el enemigo avanzó sobre Marialba y Carpio con cuatro regimientos de caballería y dos regimientos de infantería. Nuestros piquetes se retiraron detrás de la Azaba. El enemigo se retiró nuevamente alrededor de las cuatro de la tarde (Fitzclarence, 1851: 204).

Pero además de la acción intimidatoria de la artillería, las tropas de ambos ejércitos entraron en contacto (Beamish, 1832: 273). La acción tuvo lugar en el entorno de Carpio cuando el Regimiento 76 de Línea francés se vio amenazado por una fuerte columna británica. 
El general Ferey persiguió la columna aliada y se apoderó de Carpio con dos compañías del $15^{\circ}$ Ligero apoyadas por dos pelotones de Dragones y el $15^{\circ}$ de Cazadores a caballo. Después de intercambiar fuego de mosquete y pistola, la infantería y caballería británicas se retiraron del pueblo. Los franceses conquistaron e incendiaron el cuartel de la guardia en Carpio, pero no antes de que los ingleses hubieran hecho señales de fuego. En menos de una hora, las tropas de varios puestos aliados de los alrededores se habían reunido en el barranco entre Carpio y Marialba para lanzar un contragolpe. Con unos 1.500 caballos y entre 6.000 y 7.000 infantes, apoyados por seis piezas de artillería ligera y dos piezas de campaña situadas detrás de un terraplén entre Carpio y Marialba, avanzaron en línea contra los franceses (Horward, 1984: 173).

Tras este suceso los generales franceses comprendieron la necesidad de ocupar las alturas de Carpio y Marialba para controlar el estrecho desfiladero que tendría que atravesar el enemigo para atacar sus posiciones. Por este motivo el 23 de junio los franceses lanzaron otra incursión. El general Ney ordenó a tres brigadas de caballería atacar la vanguardia de Craufurd junto al Azaba. Los franceses instalaron una batería artillera en la orilla derecha del río, en la dehesa de Capilla (Horward, 1984: 187). Fitzclarence indica en su diario (1851: 207) que a las ocho en punto de la mañana, los franceses avanzaron sobre Carpio y Marialba, con fuertes cuerpos de caballería. Disparando algunos cañonazos contra Marialba con una pieza de campaña situada en la colina de la margen derecha del Águeda. La escaramuza, que duró varias horas, se saldó con la muerte de varios caballos británicos, pero sin tener que lamentar bajas humanas (Beamish, 1832: 273). Sin embargo, los puestos avanzados tuvieron que replegarse a la orilla izquierda de la rivera:

Nos vimos obligados a retirar nuestro piquete de caballería de Carpio; nuestros puestos avanzados están ahora en el vado sobre el Azaba (llamado vado Carpio) y en el puente de Marialba y el vado del Molino de Flores sobre el Águeda, que se encuentra en el cruce con el Azaba (Simmons, 1899: 73).

A partir de este día las avanzadas británicas estaban ya en constante situación de alerta. Solo desmontaban de noche, momento que aprovechaban para limpiar sus caballos.

Por la noche los hombres duermen en sus posiciones con las riendas en las manos, listos para salir en un instante. A las dos de la mañana, todos salen y permanecen en sus puestos de alarma hasta que los piquetes son relevados, entran y todo está tranquilo (Tomkinson, 1894: 25).

E1 28 de junio tuvo lugar un breve intercambio de disparos en el puente de Marialba. «Aproximadamente a las 2 en punto de la mañana, algunos de los hombres del puesto que custodiaban el puente sobre el Azaba avanzaron hasta nuestros centinelas y fueron recibidos a tiros de carabina» (Koch, 1850: 80). Por la tarde de ese mismo día, un sargento británico del $1^{\circ}$ de Húsares mantuvo conversaciones con el general francés Junot en Marialba (Fitzclarence, 1851: 210).

Al día siguiente, los centinelas identificaron a un general francés reconociendo el puente de la Azaba, lo cual era un indicio de que intentarían cruzarlo en breve (Fitzclarence, 1851: 210). Enterado el general Craufurd, esa misma tarde hizo retroceder a su división desde Gallegos a La Alameda y una vez allí, le ordenó moverse en pequeños grupos y levantar mucho polvo, con objeto de engañar a los franceses sobre la llegada de refuerzos a la zona. Para sostener los piquetes avanzados dejó en Gallegos tres escuadrones de Húsares y dos cañones (Tomkinson, 1894: 30).

A pesar de su retirada a la orilla izquierda, los británicos no volaron el puente de la Azaba sino que tan solo se limitaron a bloquear su acceso colocando una barricada formada con carros requisados a los vecinos de la zona. El 1 de julio los franceses avanzaron al oeste de Ciudad Rodrigo con varias unidades. Entre ellas «el $1^{\circ}$ de Dragones de Sainte-Croix ocupó la 
zona a la izquierda de Marialba, mientras una compañía de granaderos y dos de voltigeurs se apostaron en el camino que llega al puente de cuatro arcos, sobre la Azaba» (Horward, 1984: 214). Desde las alturas de Cuellar, Craufurd y sus oficiales observaron el despliegue francés y los cañones situados en Marialba amenazando las avanzadas (Fitzclarence, 1851: 213).

El 3 de julio el capitán Tomkinson, que estaba de guardia en el piquete del puente observó cómo los franceses se acercaban y trataban de retirar los carros que bloqueaban el paso. De inmediato dio aviso de que el enemigo pretendía cruzar la rivera y se pusieron en alerta las reservas disponibles en Gallegos. A última hora de la tarde, el general Craufurd y su Estado Mayor bajaron a la Azaba a revistar los piquetes de vigilancia. Uno de sus oficiales se acercó al puente para intentar hablar con los centinelas franceses, aunque en realidad pretendía obtener información sobre los preparativos que se hacían en la otra orilla:

Observé que estaban construyendo un puente de madera a poca distancia a la izquierda del primero, y por la apariencia agotada del forraje en el otro lado, porque habían eliminado los carros del bloqueo del puente de piedra y ciertos informes de desertores, parecía muy probable que avanzaran sobre nuestras posiciones a la mañana siguiente, el 4 de julio (Warre, 1909: 141).

Y así fue. Al amanecer del 4 de julio el general Junot con mil doscientos caballos, cinco batallones infantería y dos cañones cruzó la rivera sobre los dos puentes y avanzó sobre los piquetes británicos obligándoles a retroceder a la carrera hacia Gallegos (Belmas, 1837: 249). Solo se trataba de un reconocimiento en profundidad para determinar la fuerza enemiga y su despliegue, pero en los alrededores de Gallegos se produjeron varios combates. El más destacado fue el sostenido por el capitán Krauchenbergh que con 30 hombres del $1^{\circ}$ de Húsares de la King 's German Legion se enfrentó al $1^{\circ}$ Provisional de Dragones y un pelotón de Húsares franceses mandados por el coronel Grandseigne. Afirma Fririon (1841: 22) que este reconocimiento y el contacto con el enemigo produjo en las filas francesas las siguientes bajas: «siete oficiales y trece suboficiales y soldados franceses resultaron heridos, cuatro hombres y siete caballos fueron muertos» ${ }^{6}$.

Desde este día la División Ligera británica quedó situada entre Almeida y La Alameda y por tanto alejada de la rivera de Azaba y el puente de Marialba $10 \mathrm{~km}$.

Ya sin oposición, el 13 de julio el general Ney movió su $6^{\circ}$ Cuerpo de Ejército hasta la orilla derecha de la Azaba. Situó su flanco derecho en Marialba y el izquierdo en dirección de Aldeanueva con grandes destacamentos desplegándose hasta Espeja y Gallegos.

Loison condujo la brigada de Simon hacia Marialba y Palacios. La brigada de Ferey avanzó a Carpio con columnas de reconocimiento bajando por el camino, a dos millas más allá de Gallegos. Apoyado por la caballería de Trelliard, el despliegue de Loison se extendió desde más abajo de Sexmiro hasta el norte, en línea circular pasando por Espeja, y desde Aldea Nueva de Azaba a Carpio, situado al sur.

El $15^{\circ}$ Ligero fue apostado a la izquierda de Gallegos; un destacamento de chasseurs de siége estaba situado en los bosques delante del pueblo; el $3^{\circ}$ de Húsares adoptó una posición

6 Los listados publicados por Martinien (1899) han permitido identificar a los fallecidos en el combate de Gallegos del 4 de julio de 1810. Del $2^{\circ}$ Regimiento Dragones los subtenientes Manuel Goutierrez, Nicolás Libault de 25 años, y Jacques Mimin, de 38 años, que resultó herido, pero falleció cinco días más tarde. Del $3^{\circ}$ Regimiento de Húsares Charles Emile de Geloès, de 23 años. Y del $4^{\circ}$ Regimiento de Dragones el subteniente Leleu. Entre los heridos había un Ayudante de Campo del Estado Mayor, el capitán Jules César Suzanne Lemercier d'Equevilley, Barón d'Equevilley. Se le dio por muerto pero lo cierto es que logró restablecerse de sus numerosas heridas. Probablemente a él se refería Warre (1909: 147) con estas palabras: «Dos oficiales franceses y algunos soldados resultaron gravemente heridos. Se tomó un prisionero, sin embargo, pobre diablo, estaba cubierto de heridas, seis en la cabeza, su brazo casi cortado, el cuerpo atravesado, y es maravilloso decirlo: Se espera que se recupere» 
detrás de él y una compañía de voltigeurs preludiada en las dos iglesias de la calle principal. El $32^{\circ}$ de Línea, unido al ala derecha del $15^{\circ}$ Ligero, ocupó una posición al frente y a la izquierda del cuartel general de Trelliard en Carpio; el $25^{\circ}$ de Dragones fue apostado al sur en dirección a Espeja. Una segunda línea de posiciones incluía la Legión Hannoveriana en el puente del Azaba y puestos en los altos de Sexmiro, el $26^{\circ}$ de Línea en Marialba, la Légion du Midi en Palacios con el parque de artillería, el $15^{\circ}$ de Dragones a la derecha de Carpio y el $66^{\circ}$ y $82^{\circ}$ de Línea en Hincapié (Horward, 1984: 258-259).

\subsection{SEgundo CIClo DE ACTIVIDAD: PRIMAVERA DE 1811}

De los datos que se han expuesto hasta aquí se deduce que la mayoría de las escaramuzas tuvieron lugar en la línea Marialba - Palacios y, en cualquier caso, siempre sobre la orilla derecha de la Azaba. La única excepción fue el ligero tiroteo ocurrido en el puente a las dos de la mañana del día 28 de junio, debido más al miedo nocturno de los centinelas que a una operación ofensiva de gran envergadura.

A partir de este momento el ejército francés inició su aproximación a la frontera y, tras el breve asedio de Almeida, continuó su avance hacia el interior de Portugal como la ola imparable de un tsunami. Sin embargo, una vez alcanzó la línea de Torres Vedras y ante la falta de suministros, la ola francesa comenzó a retroceder sobre sus propios pasos. Pero esta vez el ejército napoleónico en lugar de perseguidor se convirtió en perseguido. Así, diez meses más tarde, las tropas francesas volvían a cruzar la rivera de Azaba para buscar amparo en Ciudad Rodrigo. Y lo hacían acuciados por el hambre.

El 5 de abril de 1811 la vanguardia del $2^{\circ}$ Cuerpo francés llegó a Gallegos. Se estableció frente a dicha población vigilando los caminos de Almeida, Fuentes de Oñoro y Espeja. Por su parte, el general Mássena acampó en Carpio y Marialba, detrás del Águeda. El general Loison cubrió las alturas por delante de Ciudad Rodrigo, a caballo del camino a Fuenteguinaldo, y la caballería ligera se extendió entre Carpio y Marialba para unir el $2^{\circ}$ Cuerpo y el $6^{\circ}($ Koch, 1850: 441). Al día siguiente se produjo un intercambio de disparos de fusil entre los puestos avanzados del $2^{\circ}$ Cuerpo, que estaba en Gallegos y un grupo de caballería inglesa, (Fririon, 1841: 186) y a mediados del mismo mes, la División Ligera volvía a desplegarse en sus antiguas posiciones: «Marché a Molino de Flores y encontré la División Ligera en las alturas, esperando avanzar para interceptar un convoy en el camino de Salamanca a Ciudad Rodrigo, pero no tuvo efecto nuestro propósito y regresé al campamento» (Simmons, 1899: 165). También el capitán John Kincaid señala que la División Ligera continuaba manteniendo la misma línea de puestos de vigilancia, pero además añade que «hubo algunos asuntos delicados entre los piquetes en el puente de Marialba» (1847: 73).

Durante este mes de abril, la principal preocupación del mariscal Mássena fue obtener víveres para los restos de su ejército. Debido a la falta de forraje cada quincena morían más de 700 caballos franceses. Para salvar los pocos animales que le quedaban fue preciso llevarlos a Madrigal y que allí pudieran comer. Al mismo tiempo la guarnición francesa de Almeida se encontraba bloqueada y ya sin víveres, esperando un socorro externo que no llegaba. El 17 de abril, Mássena envió a Fririón, su jefe del Estado Mayor, de Salamanca a Ciudad Rodrigo para que informase de las posibilidades de enviar un convoy de víveres a Almeida. Con este objeto se le ordenó al general Marchand realizar un reconocimiento profundo y tratar de llegar lo más cerca de dicha plaza portuguesa (Koch, 1850: 494). El día 23 Marchand salió de Ciudad Rodrigo con dos mil infantes y un escuadrón de caballería (Napier, 1839: 312), (Simmons, 1899: 165). Pero cuando trató de cruzar la rivera de Azaba sus hombres se encontraron con los británicos, que controlaban de nuevo la posición y que no cedieron sus puestos. Con esta y otras noticias remitidas por sus espías, Fririón informó a Salamanca que los ingleses se habían 
situado entre Ciudad Rodrigo y Almeida y que sería necesario librar batalla para socorrer a Almeida (Fririon 1841: 194), (Napier, 1852: 90). Efectivamente, pocos días más tarde, tuvo lugar la batalla de Fuentes de Oñoro.

Sobre este episodio, protagonizado por las fuerzas del general Marchand, las fuentes francesas apenas dan detalles. Fririon lo silencia por completo y en su narración apenas indica actividad durante la jornada del 23. Por su parte Guingret, se limita a indicar los efectivos de Marchand sin entrar en más detalles:

el 23 del mismo mes, el general Marchand, a la cabeza de 2.400 hombres lanzó una descubierta sobre el puente de Marialba, a dos leguas de Ciudad Rodrigo. Encontramos al enemigo en el puente en bastante buena forma y verificamos que Wellington bloqueaba Almeida (Guingret, 1817: 197-198).

Sin embargo, hay varios testimonios británicos bastante detallados cuya combinación permite reconstruir parcialmente las circunstancias del suceso. Uno de ellos es la escueta noticia de la acción que transmitió el duque de Wellington. En su despacho fechado el 1 de mayo en Vilar Formoso informaba que el enemigo atacó el día 23 los piquetes del Azaba, pero fue rechazado. Que los capitanes Campbell y Dobbs del Regimiento 52 y el teniente Eeles del 95 de Rifles se distinguieron en dicha ocasión y que las tropas aliadas defendieron sus posiciones frente a fuerzas enemigas muy superiores en número. Además, reconocía que un teniente y 17 soldados habían resultado heridos (Gurwood, 1844: IV, 781). No obstante, hay que añadir que Wellington redujo considerablemente la cifra de heridos, pues solo en el Regimiento 52 sufrieron 26 bajas.

Otro testimonio, mucho más extenso y detallado lo transmite John Dobbs (1859: 11-13), también capitán del 52 de Infantería Ligera y además hermano del capitán Joseph Dobbs que se distinguió en la defensa del puente y que unos meses más tarde fallecería durante el asalto británico a Ciudad Rodrigo.

El relato de John Dobbs informa que sobre el puente de la Azaba estaba desplegada la compañía del capitán Robert Campbell comandada por el teniente Henry Dawson y una sección del 95 de Rifles bajo el mando del teniente Eeles. Además, había otra compañía situada en el vado del Molino de Flores, 1,5 km al norte del puente, al mando de su hermano. También relata la rutina diaria en las posiciones británicas de la rivera. El relevo de las fuerzas desplegadas en los piquetes avanzados de la Azaba llegaba siempre una hora antes de amanecer, pero los soldados que entraban de guardia y los salientes permanecían en sus puestos hasta que la luz del día les permitía comprobar que no había enemigos a la vista. La noche del 22 de abril llovió intensamente y eso hizo que aumentase el caudal de la rivera y del río. Por tanto, el vado del Molino de Flores resultaba imposible de pasar. El día 23 tanto la compañía saliente como la entrante en ese punto pertenecían al Regimiento 52 de infantería. El relevo lo efectuaba el capitán Joseph Dobbs. Pero justo cuando se hizo de día, a las 7 de la mañana, escuchó un fuerte tiroteo hacia el puente. Tras verificar que el vado era intransitable por la crecida, dejó un cabo y tres soldados para vigilarlo y salió corriendo con el resto de sus hombres hacia el puente.

Entre que Dobbs escuchó los primeros disparos y llegó a la zona con su compañía debieron transcurrir, por lo menos, unos 10 minutos. No obstante, según indica el relato, llegó muy oportunamente, pues el enemigo había forzado el paso. Es decir, había pasado el puente. Al ver desde las alturas la situación, no dudó en atacar a los franceses. El relato continúa indicando que Dobbs colocó a sus hombres sobre las rocas en la orilla inglesa del puente, desde donde mantuvieron un fuego tal que los enemigos no pudieron volver a cruzarlo por segunda vez. Quizá para distraer la atención del hecho principal o para rebajar tensión al suceso, Dobbs describe la forma en que los franceses avanzaban para atravesar el puente. Por delante y guiando a los soldados, iba un tambor redoblando una marcha que los británicos habían bautizado como «pantalones viejos» y que probablemente se trataría del paso de carga que los franceses acos- 
tumbraban a realizar «avec grand bruit de caise» (Fririon, 1841: 155). Mientras sobrevivió el tambor, las tropas continuaron avanzando, pero en cuanto las balas británicas lo derribaron y cesó el redoble, los soldados franceses dieron media vuelta y corrieron, hasta que sus oficiales los detuvieron y les obligaron a volver a intentarlo. Aunque según las fuentes británicas ya no lograron cruzarlo de nuevo. La acción se prolongó bastante y no cesó hasta que, desde Gallegos y en apoyo de los piquetes, llegaron los dos batallones del Regimiento 52. Solo entonces los franceses regresaron hacia Ciudad Rodrigo (Moorsom, 1860: 141-142).

Los datos aportados por los testimonios británicos permiten deducir que el combate, además de largo resultó muy intenso. Primero porque, aunque los franceses solo pretendían realizar un reconocimiento, eran más de 2.000 hombres y los británicos unos 200. Segundo porque estos últimos sufrieron, solo en el Regimiento 52, 26 heridos (Moorsom, 1860: 454). Y tercero porque, aunque resultó ileso el propio capitán Joseph Dobbs le dijo a su hermano que había recibido cuatro impactos: uno en la gorra, otro en la chaqueta, otro en la solapa de sus tirantes y el otro en la hoja del sable (Dobbs, 1859: 13). Por todo lo cual se puede suponer que hubo una auténtica lluvia de balas.

\section{RESTOS MATERIALES RELACIONADOS CON ESTE COMBATE}

Durante los trabajos de prospección en la zona situada a ambos lados de la rivera de Azaba se documentaron, entre otros objetos, numerosos proyectiles esféricos. Para esbozar una posible interpretación de lo ocurrido en ese lugar era preciso, antes que nada, realizar el estudio individualizado de cada uno de ellos. Determinar, con la mayor precisión, su peso y su diámetro; estudiar las marcas y señales que presentan, la clase de impacto sufrido y el nivel de deformación, etc. Toda esta información se incorporó luego a la tabla con la que se gestiona el SIG de la prospección, lo cual, combinado con el lugar de hallazgo de cada proyectil, permite realizar múltiples representaciones con las cuales empezar a entender lo que ocurrió en torno al puente.

En la figura 7 se muestra la ubicación de todos los proyectiles documentados en el Sector 3 sin distinción de calibres. En ella se aprecian claramente tres zonas de gran concentración de hallazgos. Dos situadas en la orilla izquierda de la rivera y a ambos lados del camino de Gallegos. Otra en la orilla derecha justo al sureste del puente. El resto de los proyectiles aparecen muy dispersos, pero, en general, asociados al camino. Especialmente en el tramo que atraviesa las casas de Marialba. En la misma imagen se muestran también aquellos proyectiles que no presentan señales de disparo ni de impacto. Precisamente, el primer paso consistirá en centrar la atención sobre estos proyectiles que no fueron disparados, pues nos facilitarán una información relevante.

Es importante saber que las armas británicas y las francesas usaban calibres diferentes y por tanto el diámetro de los proyectiles también era distinto. Los fusiles Brown Bess, usaban proyectiles de a 15 en libra ${ }^{7}$, con un diámetro en torno a 17,5 $\mathrm{mm}$ y un peso alrededor de $31 \mathrm{gr}$. En cambio, el fusil francés Charleville usaba balas de a 20 en libra, con un diámetro aproximado de 16,3 mm y sobre los 24 gr de peso (Dauriac, 2011: 27). También se emplearon, aunque en menor cantidad, otro tipo de armas como carabinas y pistolas cuyos calibres eran más reducidos. Entre ellas debemos tener presente la carabina francesa modelo 1793 cuya munición era de a 28 en libra con un diámetro en torno a 14 mm (Dauriac, 2011: 22). Además de esto,

Así denominados porque de cada libra de plomo que se fundía se obtenían 15 balas de ese diámetro concreto. A menor diámetro mayor número de balas se producían con la misma cantidad de materia prima. Es necesario tener presente que la libra inglesa era de 453,59 gr mientras que la francesa, más pesada, era de 489,50 gr. 


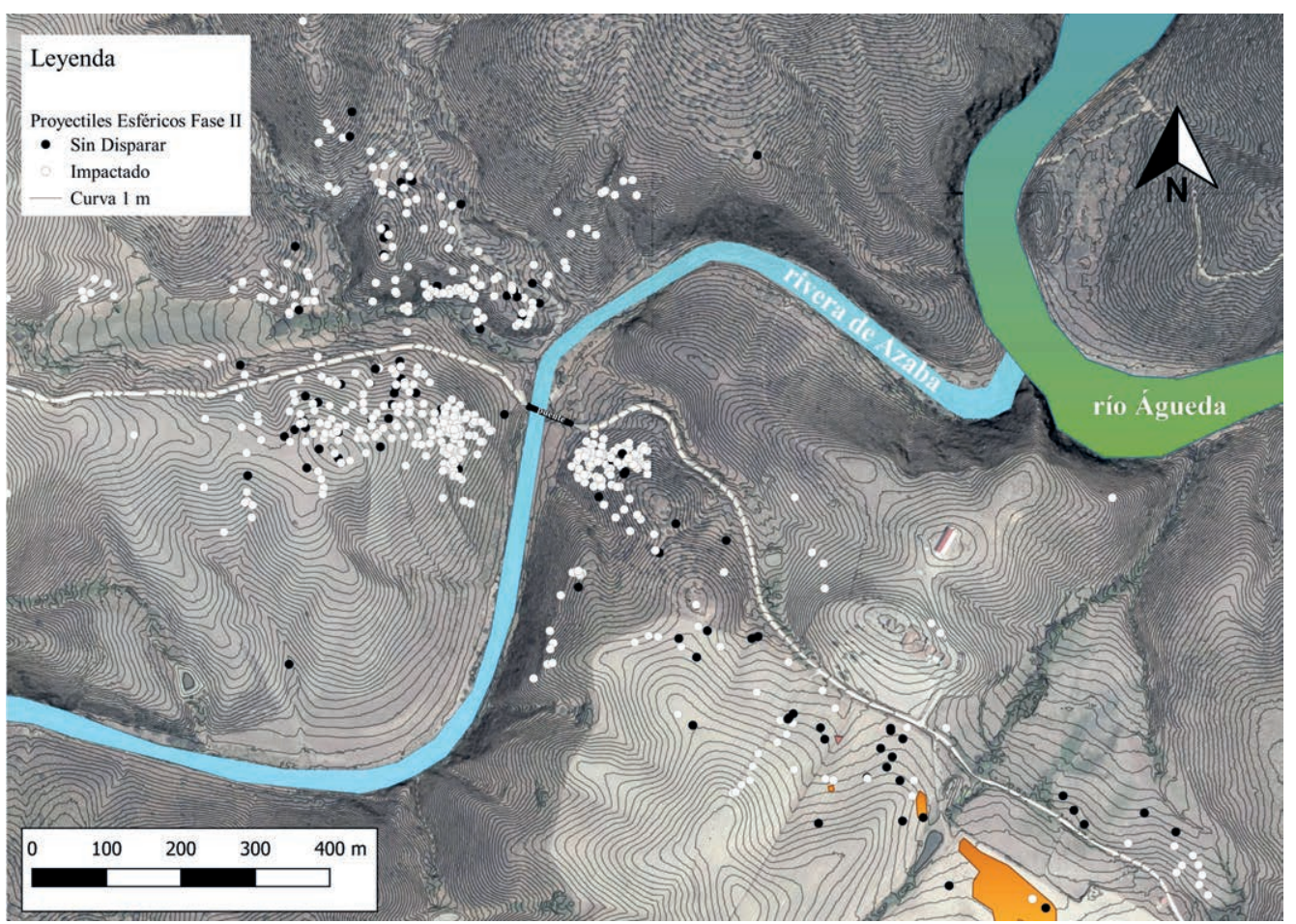

Figura 7. Concentración de proyectiles esféricos en torno al puente de la rivera de Azaba.

En blanco proyectiles disparados, en negro balas sin disparar. Clemente González 2020.

los rifles Baker, con los que estaban dotados los fusileros del Regimiento $95^{8}$ usaban balas de $a$ 20 en libra (Simmons, 1899: XVII). Según se ha visto en la documentación histórica, algunos soldados del Regimiento 95 estaban de servicio vigilando el puente el 23 de abril de 1811.

La figura 9 muestra dónde se localizaron proyectiles de estos cuatro calibres sin señales de haber sido disparados. Conviene indicar que la mayoría de los proyectiles que se recuperan sin disparar son fruto de pérdidas involuntarias. Suele tratarse de balas que se caían de la cartuchera cuando los soldados se desplegaban en sus posiciones, se sentaban o tumbaban para descansar o incluso cuando tropezaban mientras corrían. Por tanto, suelen considerarse como un buen indicador de campamentos o de puntos de despliegue ocupados por las tropas. De donde se deduce que en las posiciones británicas se deberían localizar proyectiles sin disparar del calibre británico y en las posiciones francesas proyectiles sin disparar de las armas que estos usaban. El problema surge cuando por la misma posición han pasado ambos ejércitos, como ocurrió aquí.

Esta misma imagen, en la que se representa el terreno en torno al puente con curvas de nivel separadas $1 \mathrm{~m}$, permite entender el escenario de los hechos. En la orilla izquierda de la rivera se identifican dos cotas dominantes. Al sur del camino y dentro de la finca La Puentecilla, la cota 630 es una colina cubierta de hierba, cuya ladera oriental desciende suavemente hacia el cauce de la rivera. En la misma orilla, pero al norte del camino, el terreno cambia de forma muy notable. La cota dominante es la 624 pero los desniveles son más abruptos y el suelo, abundante en rocas, está densamente cubierto de encinas. En la actualidad y también cuando

8 También disponían de ellos las tropas ligeras de la King's German Legion. 


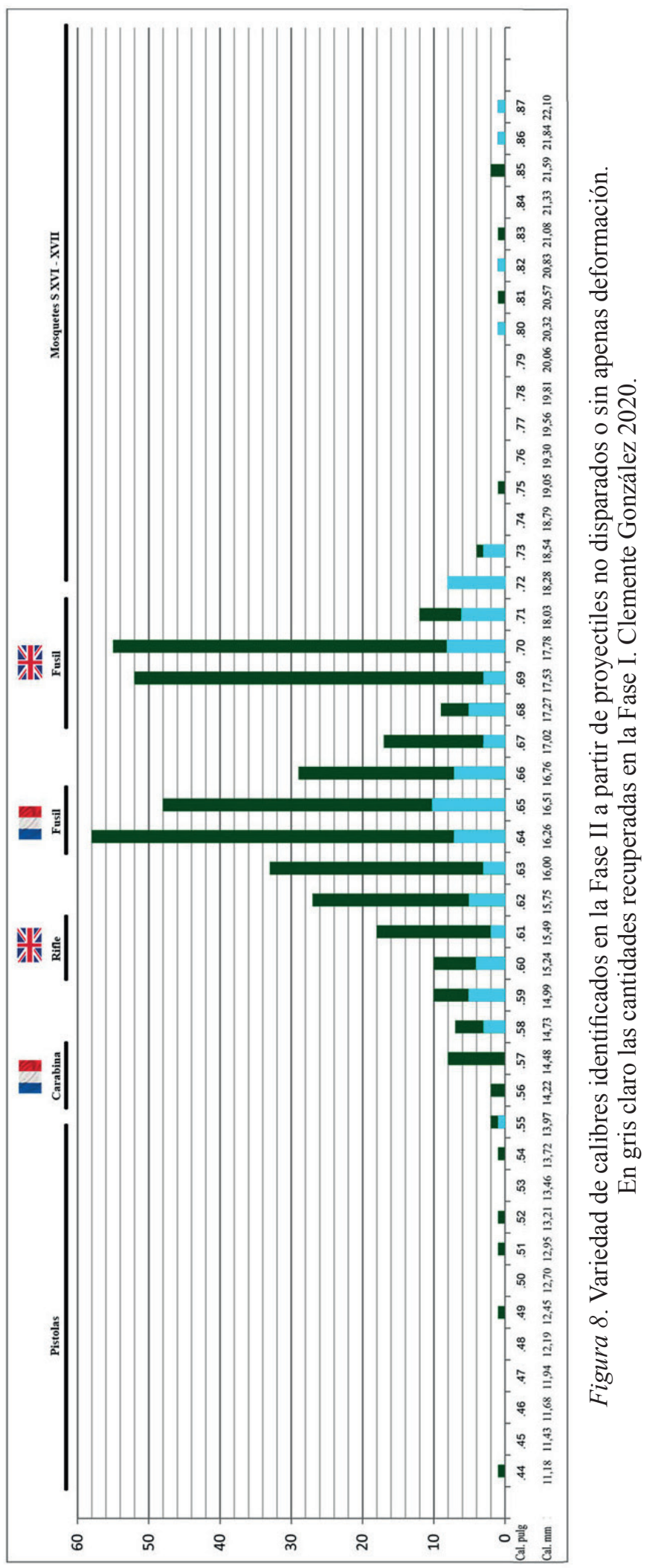

Gladius, XL (2020), pp. 153-181. ISSN: 0436-029X; eISSN: 1988-4168. https://doi.org/10.3989/gladius.2020.07 


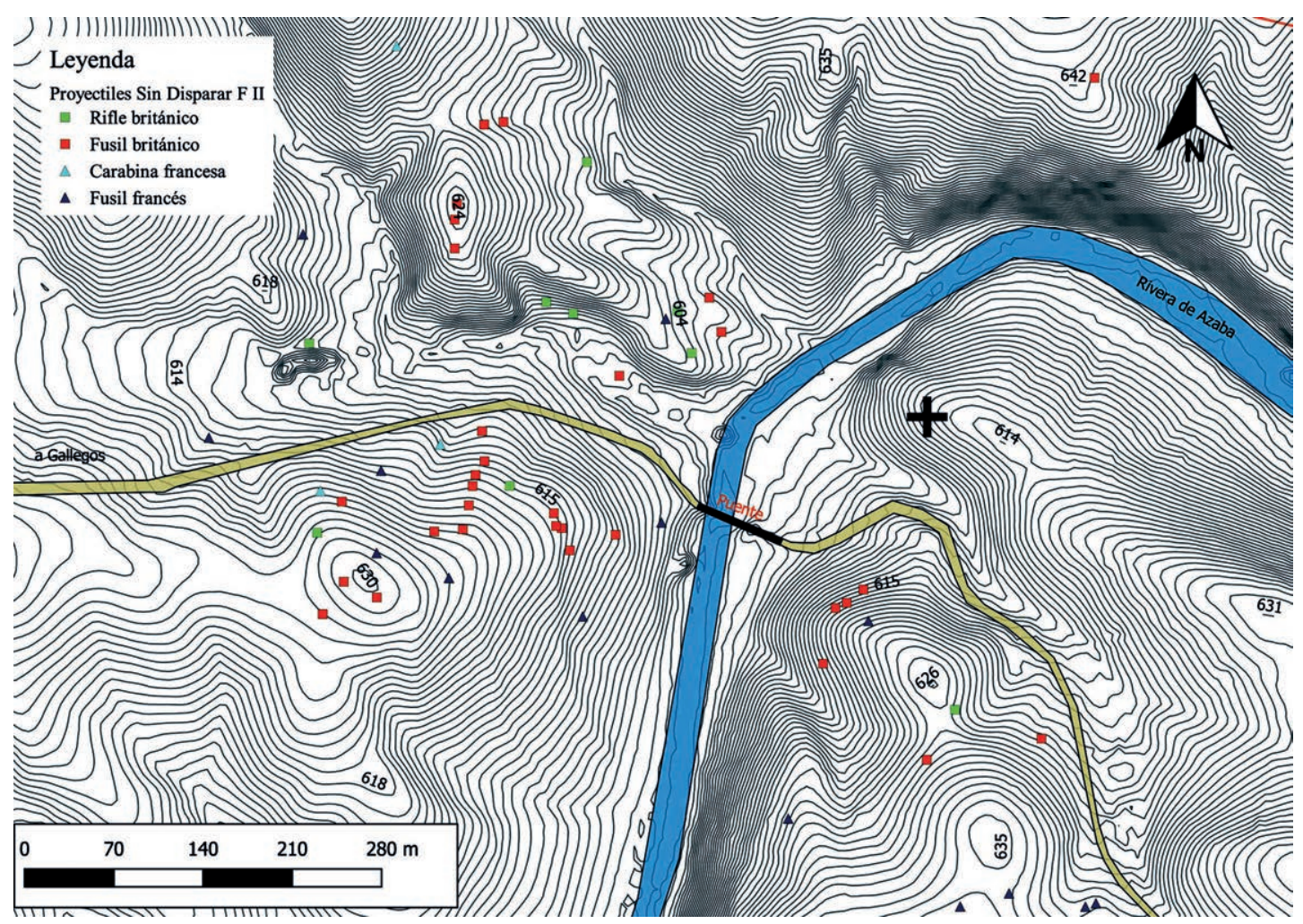

Figura 9. Proyectiles sin disparar, agrupados según su diámetro - peso por el tipo de armas que los empleaban. Clemente González 2020.

ocurrieron los hechos 9 . Estas dos cotas, la 630 y la 624 fueron las posiciones de vigilancia ocupadas por los británicos para defender el paso del puente. El problema es que ambas se encuentran a una distancia del puente de unos $300 \mathrm{~m}$ en línea recta. Para los fusiles de la época esto implicaba que los objetivos a batir, aunque dentro del alcance máximo, quedaban fuera del alcance efectivo y, por tanto, las posibilidades de alcanzar a un enemigo eran mínimas. Por esta razón los ocupantes de ambas posiciones avanzaron sus puestos hacia el cauce hasta situarse a una distancia del mismo en torno a $120 \mathrm{~m}$. En la cota 630 esta zona coincide sobre la curva de nivel de $615 \mathrm{~m}$, donde muy probablemente los británicos cavaron una trinchera paralela a la rivera. En cambio, en la cota 624 aprovecharon el espolón que avanza hacia el cauce hasta llegar a la cota 604. Puede observarse cómo sobre los puntos señalados se han localizado proyectiles sin disparar británicos. Más hacia el norte de estas posiciones, el terreno asciende notablemente y el desnivel que baja hacia el cauce se vuelve muy empinado. Desde estos riscos abruptos que superan los $640 \mathrm{~m}$ de altitud se domina, visualmente, todo el escenario del cauce y el puente. Probablemente por aquí llegaron los hombres de Dobbs. Sin embargo, estas posiciones están a más de $350 \mathrm{~m}$ del paso, por lo que los disparos de fusil realizados desde dichas cotas contra el camino tendrían muy poca posibilidad de dar en el blanco.

9 Basamos nuestra afirmación en el mapa elaborado en 1812 por José Martín Ortega, del Estado Mayor de $6^{\circ}$ Cuerpo de Ejército conservado en el Servicio Geográfico del Ejército y en el que, además de representarse dicha zona cubierta de árboles, se expresa que el «riachuelo Azabal, de orillas barrancosas, con un solo puentesillo inmediato $\mathrm{C}$ nombrado la Puentecilla y un bosque que lo atraviesa de una parte a otra». 
Por lo que se refiere a la orilla derecha, se repite el mismo proceso anterior, pero invirtiéndose. Hay también dos cotas dominantes muy próximas al cauce, aunque ambas situadas a una altura inferior a las del otro lado del puente. Al norte del camino está la 614 y al sur del mismo la 626. Pero mientras que en la orilla izquierda el terreno se eleva hacia el norte y desciende hacia el sur, en la derecha ocurre justo lo contrario. Ello implica que las tropas desplegadas sobre cada orilla podían ver fácilmente amenazado su flanco derecho. La cota 614, además de presentar un suelo abrupto y rocoso, también se encontraba densamente poblada por grandes ramos de escobas, lo cual hizo imposible el empleo del detector para prospectar su superficie. Sin embargo, durante el recorrido y casi en la cima, se documentaron restos de un monumento cruciforme realizado en cantería, derribado y al parecer expoliado ${ }^{10}$. En cambio, la cota 626, situada dentro de la finca de Marialba, a pesar de estar muy poblada de encinas, sí aportó abundantes materiales. Excepto en su cima. La diferencia tan radical de hallazgos nos dio la impresión de que la zona más elevada había sido ya prospectada con anterioridad. En dicha cota se observa un solo proyectil francés sin disparar, mientras que hay cuatro británicos. Pero hay que recordar que, desde finales de mayo hasta principios de julio de 1810, los soldados del general Craufurd estuvieron desplegados en este sector e incluso varios $\mathrm{km}$ más al este de la rivera y esa es la causa de la abundante aparición de munición británica sin disparar en la orilla derecha.

Con todo lo dicho, ya resulta evidente la distribución de las tropas en torno al puente y cuáles eran sus puntos de despliegue. A continuación, se representarán los hallazgos de aquellos proyectiles que sí fueron disparados diferenciándolos, si es posible, mediante su relación peso - diámetro para asignarlos al armamento de uno u otro bando. En este caso se descartarán tanto los anteriores sin disparar como aquellos que, por presentar señales de masticación impiden obtener una medida siquiera aproximada de su diámetro. Lo mismo se hará con los fragmentos y esquirlas de bala. Hay que tener en cuenta que, por el mero hecho de rozar el cañón durante el disparo, el proyectil ya sufre una pérdida de materia y que, tras impactar y en ocasiones rebotar, se producen también nuevas pérdidas de sustancia. Todo ello hace que un mismo proyectil pueda presentar una diferencia de peso muy notable según si está sin disparar o impactado. Recientes experimentos con fuego real han demostrado que las balas esféricas disparadas con mosquetes pierden una media del 2,4\% de su peso, cifra que, según determinadas circunstancias, puede aumentar hasta el 7,5\% (Scott et alii, 2016). En la figura 10 se muestran las balas disparadas por armas británicas y las disparadas por armas francesas. Lo primero que resulta evidente es que las concentraciones de proyectiles indican de forma muy clara las anteriores deducciones sobre la posición de cada contingente. En la cota 626 se recuperaron 124 proyectiles británicos impactados que dibujan claramente el despliegue francés sobre dicha colina. En frente, en la otra orilla, se han documentado sobre la cota 630 una cantidad aparentemente inferior, en concreto 85 proyectiles. Y decimos aparentemente, porque con dichos colores solo se han representado los proyectiles cuyo peso-diámetro coincidía con el atribuido a las armas francesas. Pero lo cierto es que se recuperaron muchísimos más que,

10 Según testimonios orales de vecinos de Gallegos dicha cruz se mantuvo en pie hasta el último tercio del siglo XX y, al parecer, fue erigida en memoria de un oficial francés que murió allí. La cruz se encuentra derribada y fragmentada en tres trozos. El tramo vertical inferior mide $130 \mathrm{~cm}$ por 40 de ancho en la base, mientras que el brazo horizontal de la cruz mide $90 \mathrm{~cm}$. Además, la losa sobre la que se alzaba muestra indicios de haber sido removida intencionadamente. A pesar de nuestras pesquisas en las fuentes documentales no hemos localizado ningún indicio que pueda confirmar la veracidad de esa tradición oral. El único caso que podría estar relacionado, sucedió el 24 de junio de 1801, cuando «Santiago Carmoi natue en Ville Colline departament de Cote de Nueble de 19 ans Carabinier au trosieme bataillon des Frans de Lorets» falleció ahogado bañándose en la ribera de la Azaba, en el término de Gallegos. Pero como su capitán afirmó que era católico fue inhumado dentro de la iglesia parroquial. Libro $2^{\circ}$ de difuntos de Gallegos de Argañán, 1763-1814. № 894, Archivo Diocesano de Ciudad Rodrigo. 


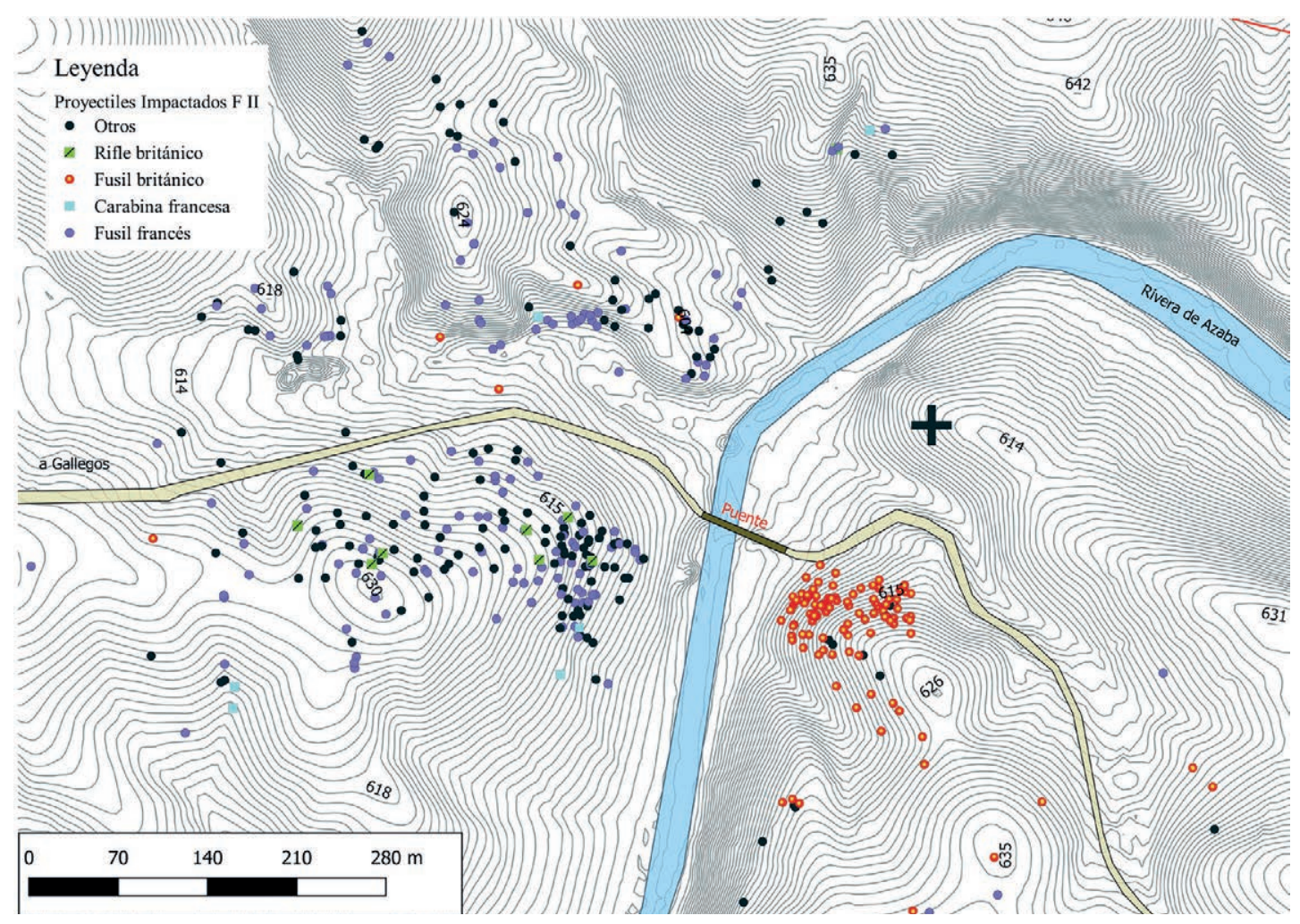

Figura 10. Concentración de los disparos de cada bando: proyectiles británicos, franceses y en negro aquellos cuyas dimensiones son más reducidas que las estándar (que en su gran mayoría podrían atribuirse al bando francés). Clemente González 2020.

a consecuencia del impacto habían perdido sustancia ${ }^{11}$. Estos últimos se representan en color negro. De esta manera la cantidad de proyectiles recuperados sobre la cota 630, pasa de 85 a 182 , a los que hay que añadir ocho proyectiles de rifle británico. En las cotas situadas al norte del camino, 618, 624, 604 y 635, se han recuperado 60 proyectiles franceses más, que ascenderían a 91 si contáramos los que no llegan a las medidas estándar.

Es importante también tener presente que los mosquetes de avancarga y ánima lisa tenían un método de puntería bastante singular. No se apuntaba sobre el objetivo, sino por encima o por debajo de él, en función de la distancia a la que se encontraba. Algo que no solo afectaba al alcance del proyectil, sino también a su energía de impacto. Por ejemplo, a los soldados españoles de esta época se les enseñaba a apuntar primero a cincuenta toesas ${ }^{12}(97,45 \mathrm{~m})$, después a ciento cincuenta $(292,4 \mathrm{~m})$ y más tarde a doscientas $(389,8 \mathrm{~m}$ ) (Reglamento..., 1812: I, 139-140). En el primer caso debían apuntar a las rodillas de los enemigos, en el segundo a la cabeza y en el tercero a la punta de las bayonetas si estaban con las armas al hombro (Salas, 1833: 395). Todo esto explica la enorme dispersión, sobre todo a nivel vertical, que presentan

11 Daniel Sivilich (Sivilich y Miller 2016) ha desarrollado una fórmula que permite calcular el diámetro de los proyectiles esféricos de plomo cuando aparecen impactados. En este caso no es posible aplicar dicha fórmula pues el principal problema no es la deformación, sino la pérdida de sustancia que presentan.

12 La toesa, como medida de longitud equivalente a 1,95 m, se introdujo en el Ejército durante la Guerra de Sucesión española, debido a que los ingenieros franceses que servían a Felipe V la propusieron como única para fortificar, fundir cañones, etc. (Salas, 1833: 17). 


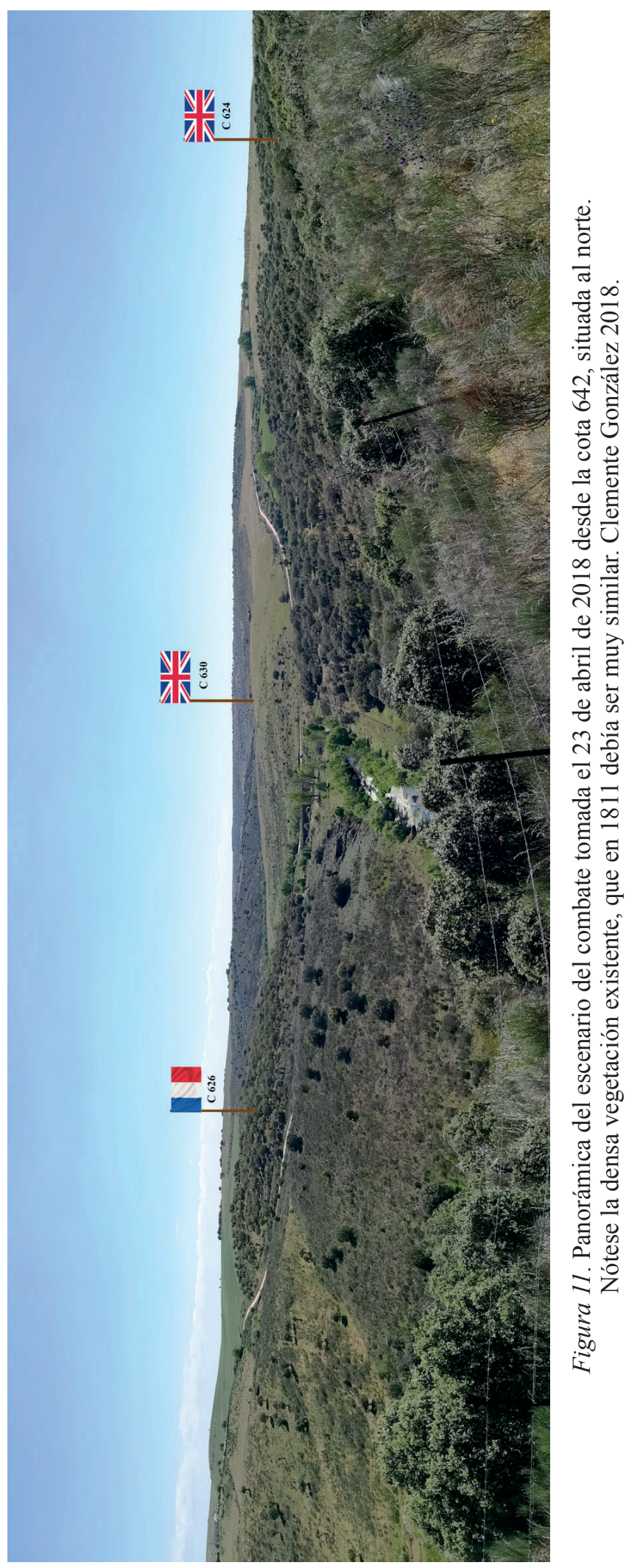

Gladius, XL (2020), pp. 153-181. ISSN: 0436-029X; eISSN: 1988-4168. https://doi.org/10.3989/gladius.2020.07 
los impactos documentados. Dispersión que podía acentuarse cuando quienes disparaban eran tropas poco experimentadas en el manejo del fusil.

A continuación, se hará una nueva clasificación de los hallazgos, pero esta vez en función del tipo de impacto que presentan las balas y su grado de deformación. Uno de los principales factores que provoca esa deformación es la energía cinética que la bala conserva en el momento del impacto. Esta viene determinada por la masa del proyectil y, especialmente, por su velocidad. El problema es que los proyectiles esféricos comienzan a perder velocidad desde el momento en que salen de la boca del arma y, según se ha demostrado en laboratorio, en los primeros 30 a $50 \mathrm{~m}$ de vuelo pierden la mayor parte de la misma en un rango de $2,5 \mathrm{~m} / \mathrm{s}$ por cada metro de distancia recorrido durante los primeros $24 \mathrm{~m}$ (Krenn et alii, 1995). De ahí que a mayor distancia entre el punto de disparo y el de impacto, menor deformación experimentará el proyectil. Y al revés, si se dispara a corta o muy corta distancia, el proyectil presentará una acusada deformación según la superficie contra la que choque. Siempre, eso sí, considerando constante el peso de cada proyectil y la cantidad de pólvora empleada en cada disparo.

Partiendo de nuestra experiencia personal en el estudio de este tipo de proyectiles, hemos realizado una clasificación, formada por cinco grupos ${ }^{13}$. El primero de ellos lo integran los proyectiles sin disparar que ya se mostraron en la figura 9. Los otros cuatro conjuntos se representarán con un color diferente, por medio de una escala graduada en la que los tonos oscuros representan los disparos lejanos y los tonos más intensos los disparos a corta distancia.

1) Impacto a Larga Distancia (ILD), azul oscuro.

2) Impacto a Media Distancia (IMD), verde.

3) Impacto a Corta Distancia (ICD), amarillo.

4) Impacto a Muy Corta Distancia (IMCD), rojo.

Este tipo de representación ayuda a reconocer la intensidad de la lucha y el nivel de violencia alcanzado. No es lo mismo mantener un tiroteo a 100 o $200 \mathrm{~m}$ de distancia, por mucho tiempo que dure, que asaltar una posición enemiga cargando a la bayoneta y disparando a quemarropa sobre sus ocupantes.

La representación de estos grupos sobre el mismo escenario, aporta interesantes datos. La figura 12 amplía la cota 626 situada sobre la orilla derecha. En ella se aprecia que predominan los impactos lejanos y también que la mayoría de los disparos parecen proceder, más que de la cota 630 situada en frente, del espolón de la 624. Además, al observarlos detenidamente muchos de estos proyectiles británicos presentan intrusiones de cuerpos extraños tal y como se observa en la figura 13. A primera vista parece que se trata de fragmentos de pizarra, contra la cual debieron impactar. De ser así, podrían estar indicando la existencia de parapetos realizados con este tipo de piedra, con la que, en la actualidad se levantan las cercas que separan las propiedades. De hecho, durante la prospección se documentaron en la zona diversas estructuras, tanto negativas como positivas probablemente de uso bélico. Entre estas últimas algunos parapetos realizados con lajas de pizarra.

Una imagen muy diferente es la que presentan los proyectiles de la orilla izquierda. En esta zona los puntos rojos, disparos a muy corta distancia, son mucho más abundantes y reflejan de forma evidente el alcance del movimiento de los franceses más allá del puente. En la figura 14 se aprecian dos direcciones de avance muy claras en torno a la cota 630. Una desde la propia orilla de la rivera y la otra desde el camino. Quizá esta maniobra envolvente de la posición, unida al intenso fuego que sufrían desde la orilla contraria, fue lo que obligó a los

13 Recomendamos al lector interesado en las cuestiones balísticas del armamento de avancarga nuestro trabajo «A corta distancia. Proyectiles esféricos de la Acción de las Useras, Castellón (17 de julio de 1839)» González, e. p. 


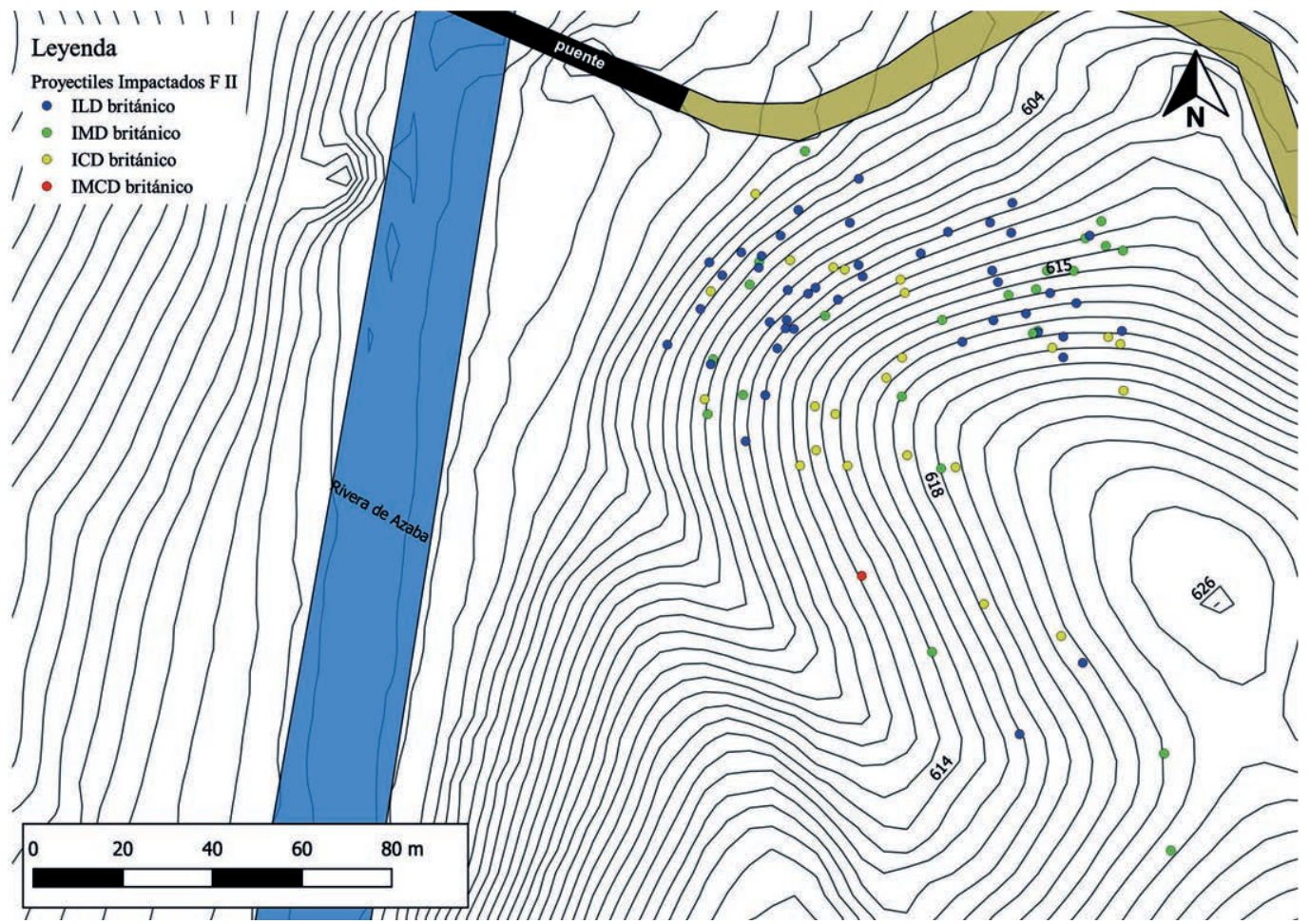

Figura 12. Proyectiles británicos impactados sobre la cota 626. Clemente González 2020.

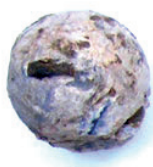

1494

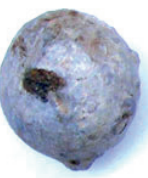

1476

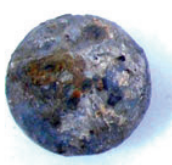

1450

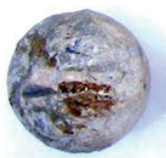

1436

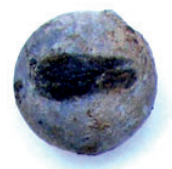

1493

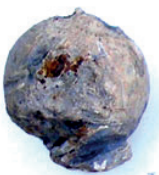

1473

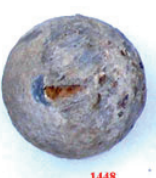

1448

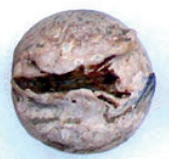

1435

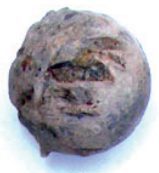

1492

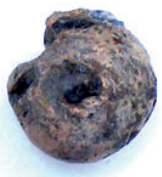

1469

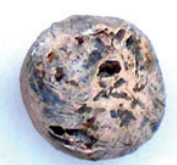

1445

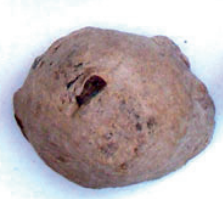

1511

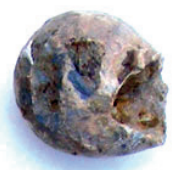

1491

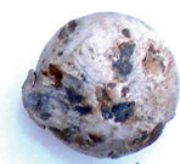

1464
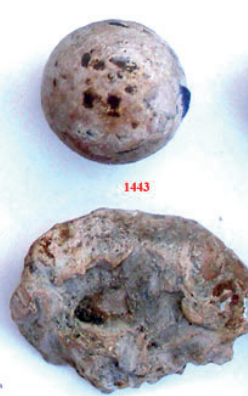

1505

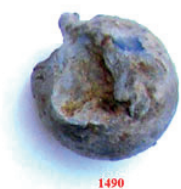

1490

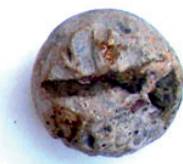

1462
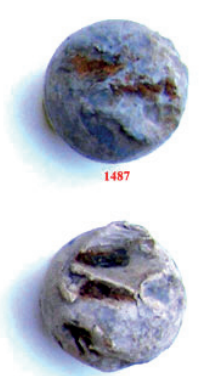

145

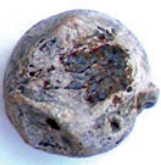

1442

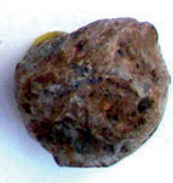

1503

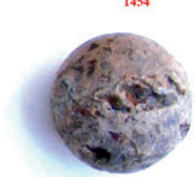

1438

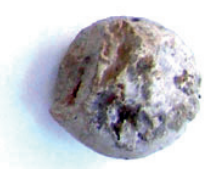

1501

Figura 13. Selección de proyectiles británicos recuperados en la cota 626 en los que se aprecia la intrusión de fragmentos de pizarra. Clemente González 2019.

Gladius, XL (2020), pp. 153-181. ISSN: 0436-029X; eISSN: 1988-4168. https://doi.org/10.3989/gladius.2020.07 


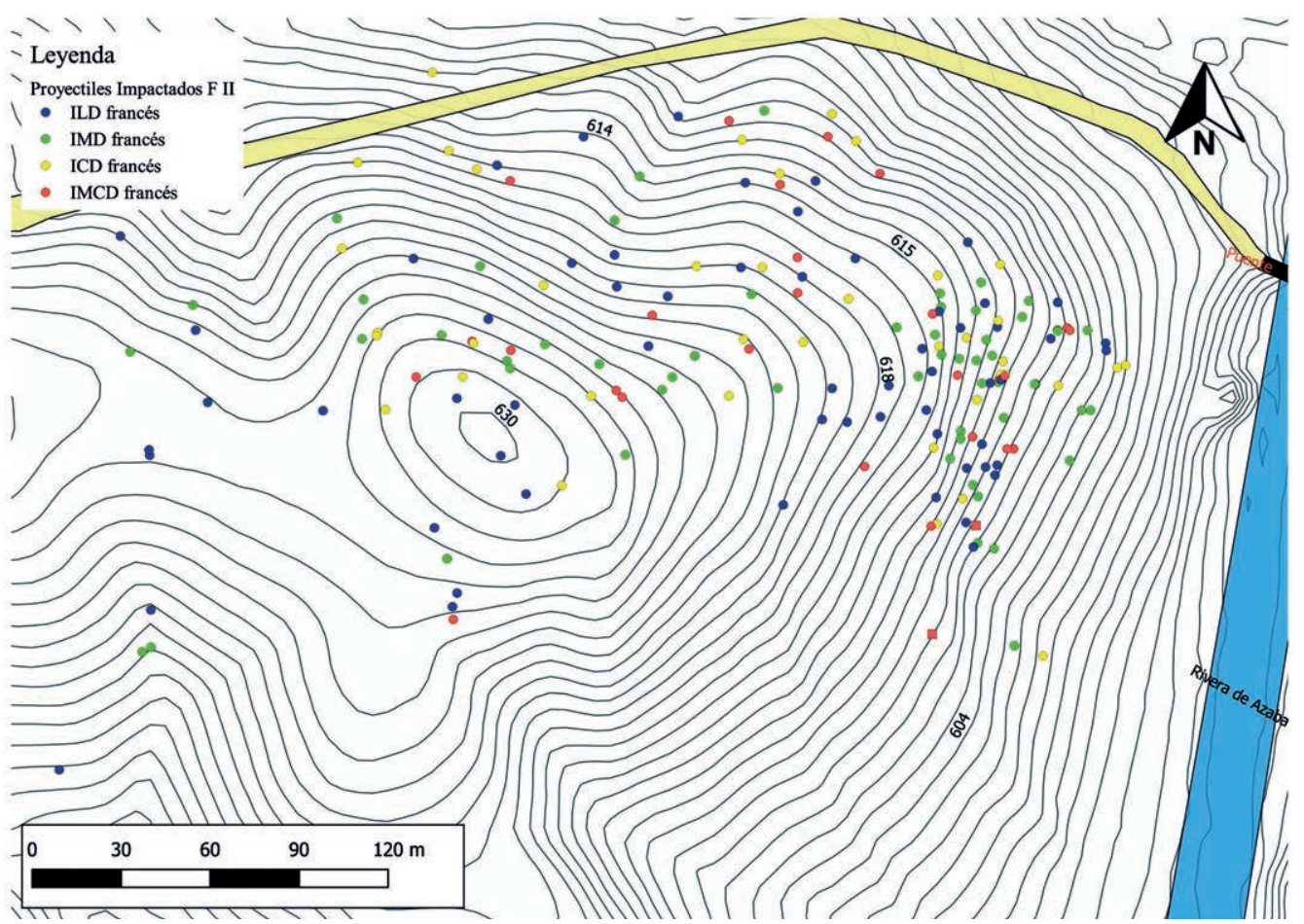

Figura 14. Proyectiles franceses sobre la cota 630. Nótese la abundancia de impactos MCD = Muy Corta Distancia. Clemente González 2020.

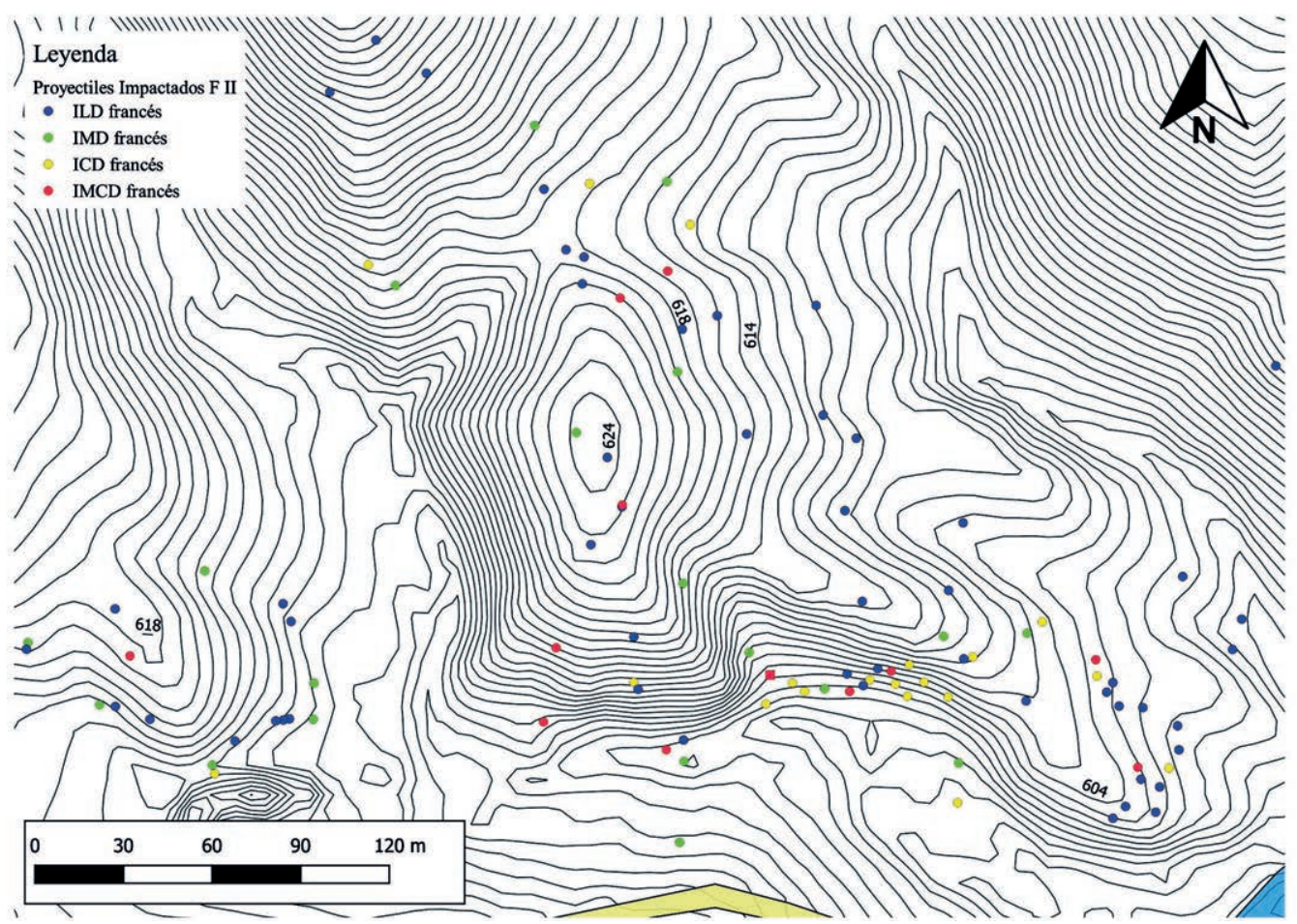

Figura 15. Impactos franceses en torno a la cota 624. Clemente González 2020. 


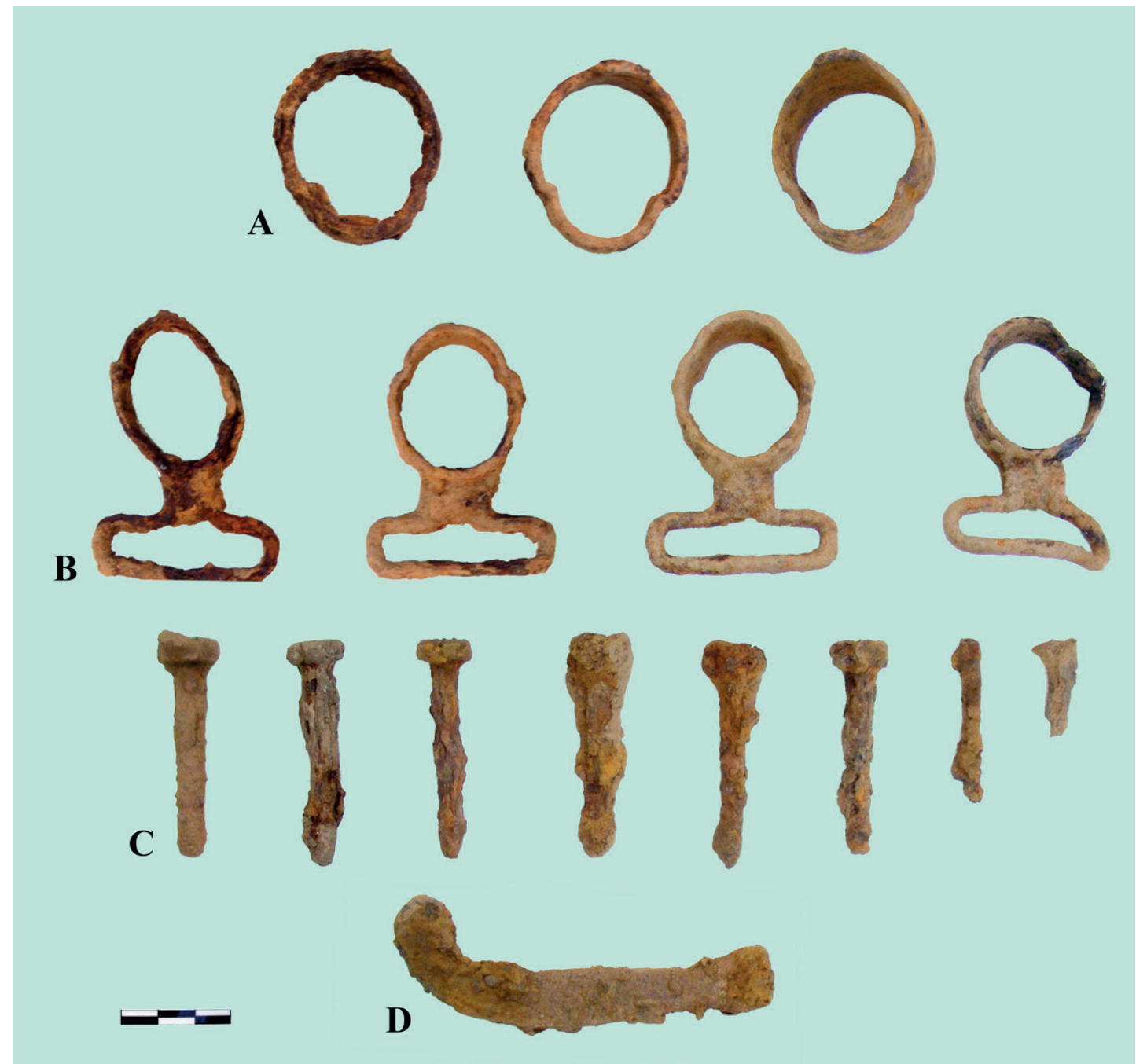

Figura 16. Herrajes de fusil francés localizados en torno a la cota 624 . A = anilla de sujeción del cañón a la caña. $\mathrm{B}=$ anilla de sujeción con enganche para la correa portafusa. $\mathrm{C}=$ tornillos de retención. D = contrapletina. Clemente González 2019.

ingleses a ceder el terreno y refugiarse entre las rocas y espolones de la cota 624 al norte del camino. Sin embargo, tampoco allí se vieron libres de sufrir un fuego intenso y cercano. La figura 15 evidencia que, también desde el camino los franceses hicieron abundantes disparos contra el espolón que ocupaban los ingleses. Hay que señalar que en el entorno de dicho espolón se documentó cierta concentración de herrajes de fusil francés, como si en dicho punto alguien hubiera inutilizado un mínimo de cuatro fusiles, figura 16. No es posible determinar si este desguace se produjo antes o después del episodio aquí estudiado, pero en cualquier caso resulta muy significativo. A lo largo de toda la prospección se documentaron más restos de armamento y equipo, como se muestra en las figuras 18 y 19, pero en ningún otro lugar se halló una concentración semejante. 


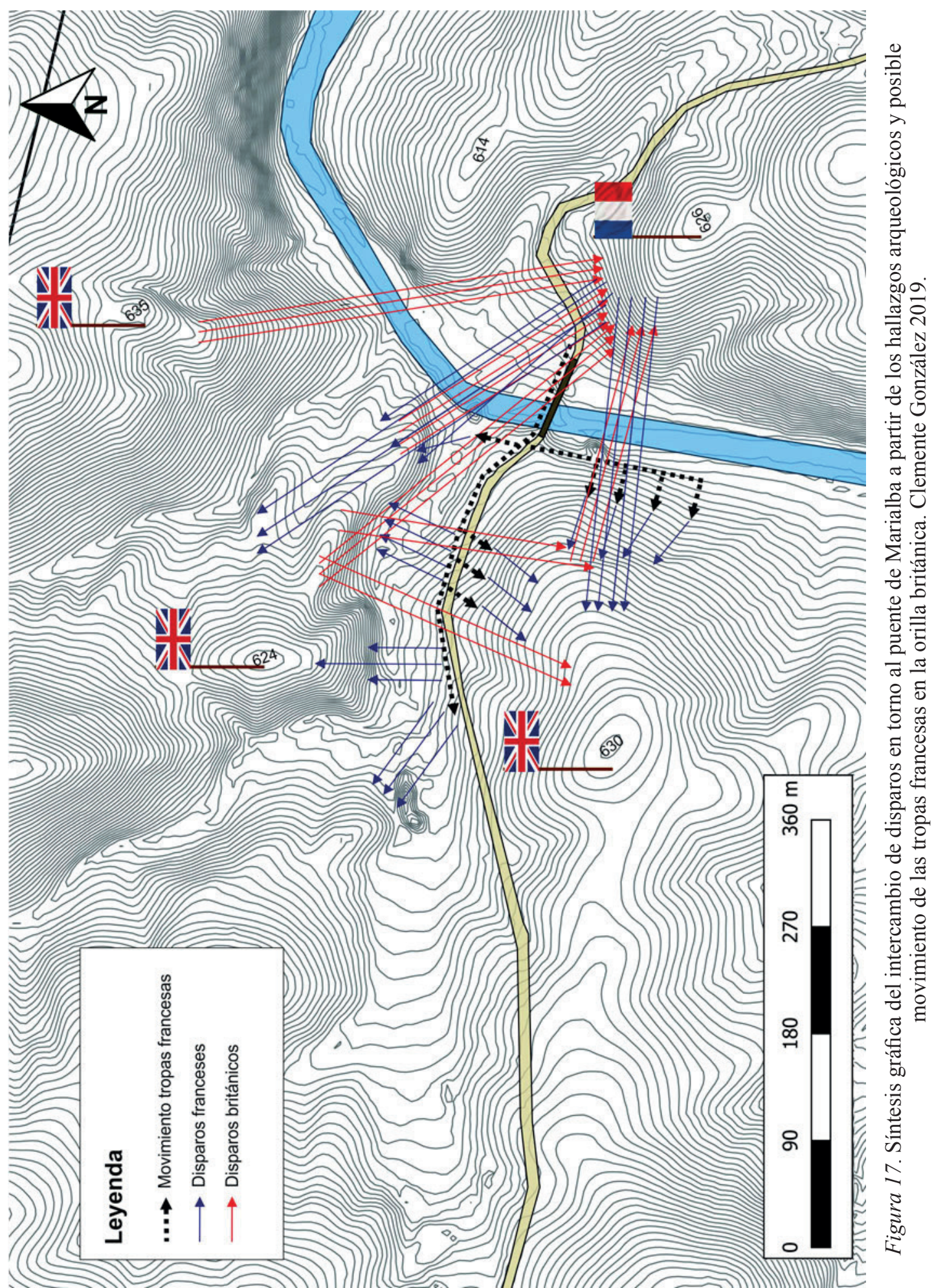




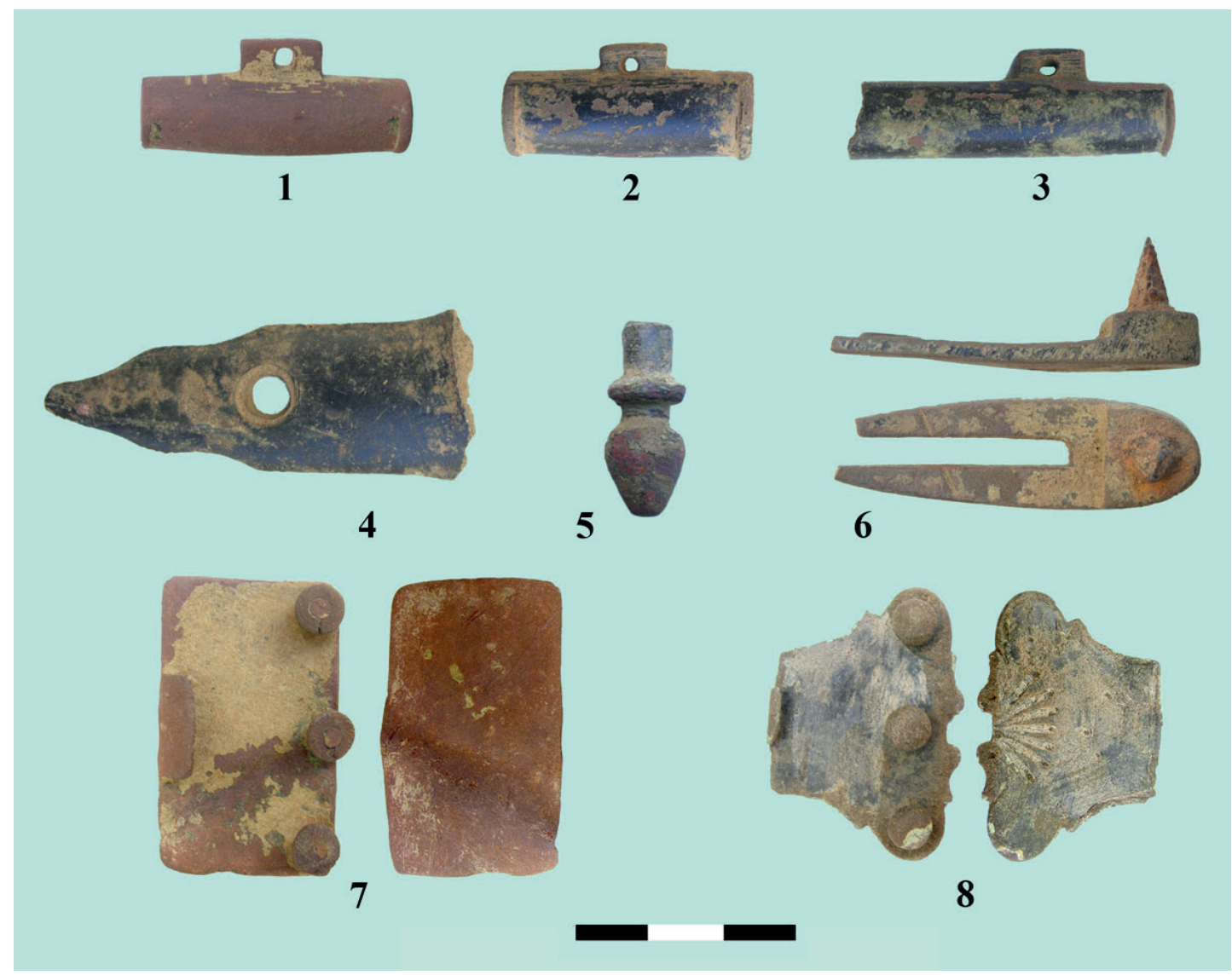

Figura 18. Selección de restos de armamento y equipo recuperados en la Fase II. 1, 2 y $3=$ porta baqueta de diversas armas. $4=$ fragmento de cantonera de fusil. $5=$ contera de bayoneta británica.

$6=$ porta gatillo de fusil británico. 7 y $8=$ enganches de correa protectora de cuello.

El número 8 se localizó muy próximo a los herrajes de fusil francés y presenta decoración neoclásica. Clemente González 2019.

\section{INTERPRETACIÓN Y CONCLUSIONES}

Los datos aportados en las ilustraciones anteriores, no solo son coincidentes con el relato que transmiten las fuentes documentales, sino que además lo amplían de una manera bastante objetiva y permiten comprender el desarrollo del combate. No obstante, y para mayor claridad, se ha elaborado una ilustración en la que se sintetizan las trayectorias de los disparos deducidas a partir de los hallazgos. En ella se incluye también el probable movimiento de las fuerzas francesas y su máximo avance.

Los hallazgos arqueológicos no solo han permitido establecer el despliegue de las tropas y sus principales posiciones defensivas. También la trayectoria de sus fuegos, cuyos alcances resultan compatibles con los de las armas de la época. Pero, además, consideramos muy probable que las tropas británicas situadas sobre el puente pudieron llegar a abandonar su posición, forzadas por la maniobra enemiga, que estuvo a punto de acorralarlas. Los hallazgos sugieren que una avanzadilla francesa, cruzó rápidamente el puente y se desplegó en guerrilla sobre la orilla de la rivera. Que ascendieron por la ladera de la cota 630 disparando a corta distancia contra los centinelas ingleses allí establecidos. Desde la orilla opuesta, sus compañeros de la 
cota 626 les cubrían disparando contra los ocupantes de la posición que intentaban asaltar. Al mismo tiempo, otras fuerzas francesas también cruzaron el puente y además avanzaron por el camino unos 300 m más allá de la rivera. Los integrantes de esta fuerza abrieron fuego desde el camino tanto a su izquierda como a su derecha. Y, a tenor de la cantidad de disparos recuperados o eran muchos, o lo hicieron durante mucho tiempo. En cualquier caso, el tiroteo duró lo suficiente como para que las reservas británicas, acampadas en Gallegos, se concentraran $\mathrm{y}$ tras equiparse y formar, salieran a la carrera recorriendo los $4 \mathrm{~km}$ que les separaban para socorrer a sus compañeros.

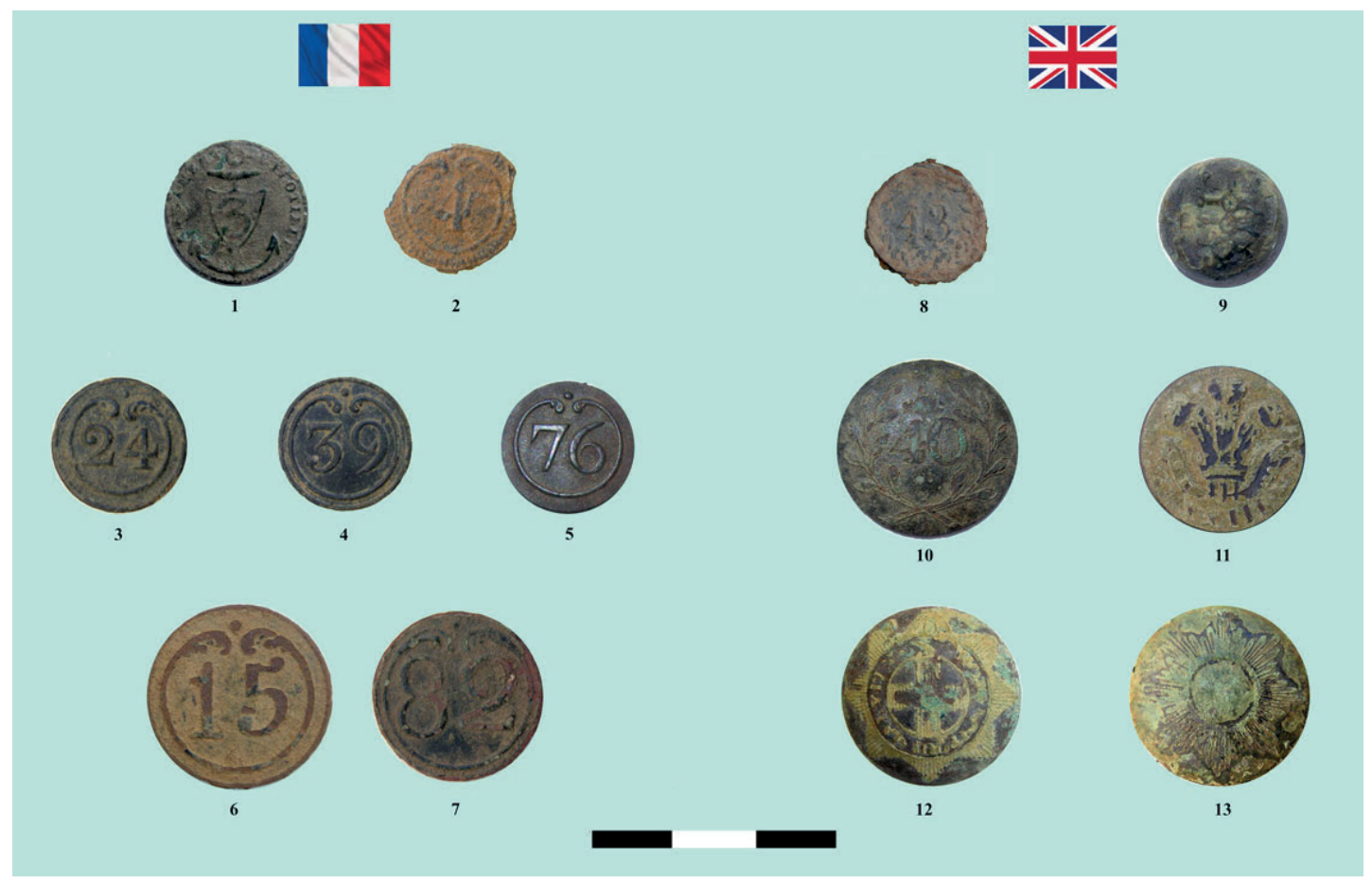

Figura 19. Selección de botones recuperados en la Fase II. Clemente González 2019.

Nuestra hipótesis de que las guerrillas francesas tomaron la cota 630, y que desde allí dispararon contra las alturas rocosas situadas frente a ellos al norte del camino, se apoya en que los proyectiles altamente deformados son muy numerosos en dicha cota. Y además, en los ocho disparos de rifle Baker localizados en la ladera de dicha posición británica. Si los británicos dispararon contra su propia posición, es porque estaba siendo ocupada por los franceses.

Por desgracia, la falta de recursos no permitió dedicar más tiempo a prospectar con mayor amplitud este sector como para documentar todos los impactos que deben existir. Sabemos por nuestra experiencia previa en este tipo de escenarios, que el porcentaje de proyectiles que se recuperan es siempre muy inferior al que se disparó. Sin embargo, a pesar de todo, salta a la vista que los hallazgos son muy numerosos. Por tanto, parece muy probable que la acción de combate se prolongó durante bastante tiempo.

Finalmente queremos destacar que el hecho de recuperar tan gran cantidad de proyectiles de plomo en torno al cauce de la rivera, no solo resulta útil para la investigación histórica. También supone un importante proceso de descontaminación al retirar del campo una gran 
cantidad de plomo, cuyas partículas tóxicas, arrastradas por la lluvia, acaban llegando a los acuíferos. Solo en la Fase II se han recuperado más de $22 \mathrm{~kg}$ de plomo en los numerosos objetos que yacían en los campos y que con frecuencia son mordidos, masticados e ingeridos por el ganado que pace en los mismos. Todo ello es, sin duda, un argumento más para potenciar la investigación de los campos de batalla. Este tipo de investigación requiere mucha menos inversión y personal que la tradicional excavación arqueológica y permite delimitar con mayor precisión las zonas susceptibles de ser excavadas. Además, aporta gran cantidad de restos materiales que incrementan el patrimonio histórico y los fondos museográficos. En nuestro caso, los 1961 objetos metálicos documentados en la Fase II, entre los que figuran nueve monedas de plata, se encuentran ya depositados en el Museo de Salamanca.

\section{CARTOGRAFÍA}

CNIG, Centro Nacional de Información Geográfica:

- MDT25-0525-H29

- 6964500 Lidar

- 696_4502 Lidar

- 6984500 Lidar

- 6984502 Lidar

- 694_4500 Lidar

- 694 4502 Lidar

- PNOA_MA_OF_ETRS89_HU29_h50_0525

\section{BIBLIOGRAFÍA}

Beamish, L. (1832): History King's German Legion. Vol. I, London.

Becerra, E. y Redondo, F. (1988): Ciudad Rodrigo en la Guerra de la Independencia. Ciudad Rodrigo, Patronato Municipal de la Casa de la Cultura.

Belmas, J. (1837): Journaux des sieges faits ou soutenus par les français dans le péninsule, de 1807 a 1814. París.

Dauriac, E. (2011): Les armes de Napoleón. Isle, Balezy.

Dobbs, J. (1859): Recollections of an old 52nd man, by captain John Dobbs, (late 52nd light infantry). Waterford, T. S. Harvey.

Fitzclarence, F. (1851): A Manual of Out-Post Ruties. A Private journal of general Craufurd's out-post operations on the Coa and Agueda in 1810. London, Shaw Kennedy.

Fririon, B. (1841): Journal Historique de la Campagne de Portugal, entreprise par les français, sous les ordres du Maréchal Masséna, Prince d'Essling, (du 15 septembre 1810 au 12 Mai 1811). Paris, librairie Militaire de Leneveu.

González García, C. (2015): Un lugar llamado Gallegos en el Campo de Argañán. Castellón.

González García, C. (2018): «Campos de Batalla en Gallegos de Argañán, Salamanca, ss XVII-XIX. Primera fase». Saguntum, Papeles del laboratorio de Arqueología de Valencia, 50, 219-240. https:// ojs.uv.es/index.php/saguntum/article/view/4990/7654

González García, C. (en prensa): «A corta distancia. Proyectiles esféricos de la Acción de las Useras, Castellón (19 de julio de 1839)». Saguntum, Papeles del laboratorio de Arqueología de Valencia, en prensa (aceptado 23-IV-2020).

Guingret, M. (1817): Relation historique et militaire de la campagne de Portugal, sous le maréchal Masséna, Prince d'Essling. Limoges.

Gurwood, C. B. (1844): The Dispatches of Field Marshal the Duke of Wellington, during his various campaigns. Vol. IV. London.

Hernández Vegas, M. (1935): Ciudad Rodrigo, la Catedral y la Ciudad. Vol. I y II. Salamanca. 
Horward, D. (1984): Napoleón y la Península Ibérica. Ciudad Rodrigo y Almeida dos asedios análogos, 1810. Salamanca, Diputación de Salamanca.

Kincaid, J. (1847): Adventures in the Rifle Brigada in the Peninsula, France and Netherlans from 1809 to 1815. London.

Koch, J. B. F. (1850): Mémoires de Massena rédigés d'après les documents qu'il a laissés et sur ceux du Dépôt de la Guerre et du Dépôt des Fortifications. Tome Septième. Paris, Paulin et Leghevalier, Libraires-Éditeurs et chez Rousseau Libraire.

Krenn, P.; Kalaus, P. y Hall, B. (1995): «Material culture and military history: test-firing early modern small arms». Material culture review / revue de la culture matérielle, 42: 101-109. http://journals. lib.unb.ca/index.php/mcr/article/view/17669/18944

Leach, J. (1831): Rough Sketches of the live of an old soldier, during a service in: the West Indies; at the siege of Copenhagen in 1807; in the Peninsula and the south of France in the campaigns from 1808 to 1814 with the Light Division; in the Netherlands in 1815; including the battles of Quatre Bras and Waterloo with an light sketch of the three years passed by the army of occupation in France. London, Longman, Rees, Orme, Brown, and Green.

Martinien, A. (1899): Tableaux, par corps et par batailles, des officiers tués et blessés pendant les guerres de l'Empire (1805-1815). Paris, Henri Charles-Layauzelle.

Moorsom, W. (1860): Historical Record of the Fifty-Second Regiment (Oxfordshire Light Infantry) from the year 1755 to the year 1858. London, Richard Bentley.

Napier, W. (1839): History of the war in the Peninsula and in the South of France from the year 1807 to the year 1814. 4th edition, Vol II. Paris, Charles Hingray.

Napier, W. (1852): English battles and sieges in the Peninsula. Extracted from his "Peninsula War". London, Chapman and Hall.

Reglamento para el ejercicio y maniobra de la infantería. (1812). Coruña.

Salas, R. de (1833): Prontuario de artillería para el servicio de campaña. Madrid.

Scott, D.; Bohy, J.; Boor, N.; Haecker, C.; Rose, W. y Severts, P. (2016): Colonial Era Firearm Bullet Performance: an experimental Study for Archaeological Interpretation. Battlefield Restoration and Archaeological Volunteer Organization. https://bravodigs.org/wp-content/uploads/2019/04/Roundball-shooting-4-13-17-final.pdf

Simmons, G. (1899): A British rifle man; the journals and correspondence of Major George Simmons, Rifle Brigade, during the Peninsular war and the campaign of Waterloo, London. Edited, with introduction, by Lieut.-Colonel Willoughby Verner Late Rifle Brigade Author of Sketches In the Soudan, Etc. With three Maps. A. \& C. Black, Soho Square. London.

Sivilich, D. M., y Miller, H. M. (2016): Musket ball and small shot identification: A guide. Norman, University of Oklahoma Press.

Tomkinson, W. (1894): The Diary of a Cavalry Officer in the Peninsular and Waterloo campaigns 18091815. New York - London, Swan Sonnenschein \& Co. - Macmillan \& Co.

Warre, W. (1909): Letters from the Peninsula, 1808-1812. London, Edmond Warre.

Recibido: 10-09-2019

Aceptado: 20-05-2020 